Article

\title{
Optimal Phase Load Balancing in Low Voltage Distribution Networks Using a Smart Meter Data-Based Algorithm
}

\author{
Gheorghe Grigoraș ${ }^{1} * \mathbb{E}$, Bogdan-Constantin Neagu ${ }^{1} \mathbb{D}$, Mihai Gavrilaș ${ }^{1}$, Ion Triștiu ${ }^{2}$ and \\ Constantin Bulac ${ }^{2}$ \\ 1 Department of Power Engineering, "Gheorghe Asachi” Technical University of Iasi, 700050 Iasi, Romania; \\ bogdan.neagu@tuiasi.ro (B.-C.N.); mgavril@tuiasi.ro (M.G.) \\ 2 Department of Power System, "Politehnica" University of Bucharest, 060042 Bucharest, Romania; \\ itristiu@upb.ro (I.T.); constantin.bulac@upb.ro (C.B.) \\ * Correspondence: ggrigor@tuiasi.ro or ghgrigoras@yahoo.com; Tel.: +04-0232-278-683
}

Received: 21 February 2020; Accepted: 3 April 2020; Published: 8 April 2020

check for updates

\begin{abstract}
In the electric distribution systems, the "Smart Grid" concept is implemented to encourage energy savings and integration of the innovative technologies, helping the distribution network operators (DNOs) in choosing the investment plans which lead to the optimal operation of the networks and increasing the energy efficiency. In this context, a new phase load balancing algorithm was proposed to be implemented in the low voltage distribution networks with hybrid structures of the consumption points (switchable and non-switchable consumers). It can work in both operation modes (real-time and off-line), uploading information from different databases of the DNO which contain: The consumers' characteristics, the real loads of the consumers integrated into the smart metering system (SMS), and the typical load profiles for the consumers non-integrated in the SMS. The algorithm was tested in a real network, having a hybrid structure of the consumption points, on a by $24-h$ interval. The obtained results were analyzed and compared with other algorithms from the heuristic (minimum count of loads adjustment algorithm) and the metaheuristic (particle swarm optimization and genetic algorithms) categories. The best performances were provided by the proposed algorithm, such that the unbalance coefficient had the smallest value (1.0017). The phase load balancing led to the following technical effects: decrease of the average current in the neutral conductor and the energy losses with $94 \%$, respectively $61.75 \%$, and increase of the minimum value of the phase voltage at the farthest pillar with $7.14 \%$, compared to the unbalanced case.
\end{abstract}

Keywords: phase load balancing; smart meters; dynamic optimization; real-time implementation; low voltage electric distribution networks

\section{Introduction}

The three-phase electric distribution networks (EDN) are designed and built to operate in symmetrical and balanced regimes on all phases with all elements (lines, transformers, and not least the distributed generation sources) having identical electrical parameters. In these regimes, the symmetrical current and voltage systems in each node of the system have equal values of the magnitudes of the voltage and currents on each phase, with a phase shift by 120 degrees. But, an ideal system of the currents and voltages is practically impossible to be met in the real operation conditions of the EDN because of the emergence of imbalances created mainly by the constructive conditions of some network elements (lines and transformers) or the supply of the single-phase (1-P) consumers. Thus, the operating regimes become asymmetric (unbalanced), the symmetry loss of the voltage and current systems [1]. 
The main causes of the imbalances in an EDN can be grouped into the following categories [2]:

- Constructive imbalances. These appear because of the spatial arrangement of the phase conductors, at the electrical lines, and the arrangement of the windings on the three columns of the ferromagnetic core, at the power transformers.

- $\quad$ Functional imbalances. These are created by 1-P consumers. They are connected between two phases or between a phase and the neutral point. Many of them are represented by domestic and tertiary consumers supplied from the low-voltage (LV) network, with small values of the absorbed power (up to $100 \mathrm{kVA}$ ). Also, there are 1-P industrial consumers. They have high absorbed powers being connected to electric medium voltage (MV) networks. The representative 1-P industrial consumers are the following: the welding installations, with absorbed powers between $100 \mathrm{kVA}$ and $3 \mathrm{MVA}$, the 1-P arc furnaces, and the electric stations that supply power the railway traction network).

The current unbalances causes many issues at all voltage levels of the electric distribution networks [3]. The issues caused by current unbalance and the effects on the voltage unbalance are presented in Figure 1, adapted after [3].

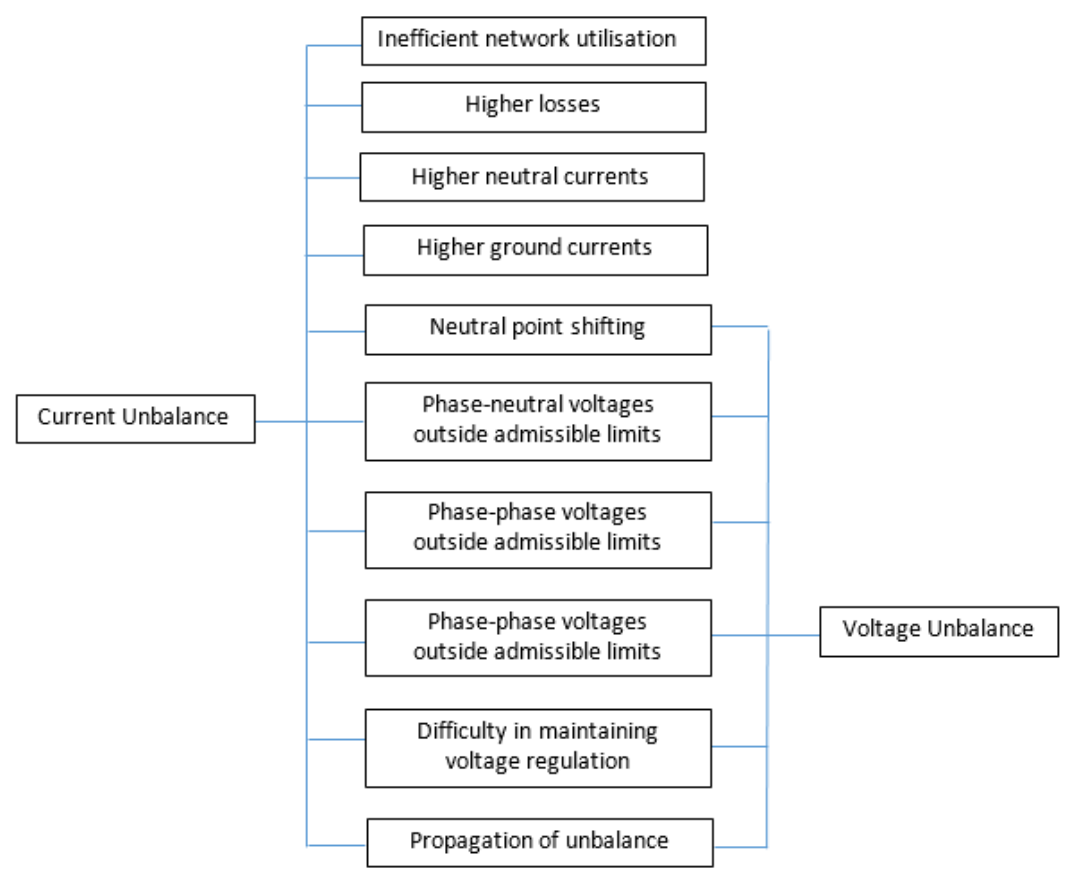

Figure 1. The issues caused by the current unbalances [3].

It can be observed that the current and voltage unbalances cannot be separately treated. In this context, the voltage unbalances could cause current unbalances, with economic and technical losses for both partners (consumers and DNO). Concerning the attenuation measures, the current unbalances can be easier solved by the DNO. The main advantage of current balancing refers to the minimization of the current flow in the neutral conductor with benefits on the decrease of the total losses in the EDN [1].

Several phase load balancing (PLB) mechanisms are found in the literature. The PLB problem was solved in [4] using the branch and bound algorithm. The aforementioned approach uses real data of customer power demand in different periods to minimize the value of unbalance factor and find the optimal three-phase load balance in an EDN. The PLB approach used in [5] considers the reallocation of the customers to reduce the unbalance level in the EDN. Other approaches use different automatic three-phase load balancing devices [6-8]. The solutions for the PLB model were obtained using various techniques and technical measures: Hierarchical Petri nets [9], LV the feeder reconfiguration [10,11], 
or switching the consumers on the three phases [12-14]. The PLB problem was solved with particular metaheuristic algorithms in [15-17]. A PLB mechanism was proposed in [18] to be used at the MV/LV power transformer level. A particular approach, based on the optimal placement of a decentralized and autonomous battery storage system, was developed in $[19,20]$. A different formulation of the PLB optimization problem is presented in [21] which follows the implementation of a commutation system, with two-phase thyristor parallel contactor structure, or based on the power-line communication (PLC) and supervisory control and data acquisition (SCADA) technologies in [22,23], and not based on smart meters [24,25]. Another category of the published papers [26-28] regards the PLB problem at the active distribution networks (smart grids) level, using heuristic or metaheuristic methods. Moreover, an automatic phase load balancing device [29], a shunt passive compensator [30], or a controlled active filter [31] were proposed. Also, a controller was proposed in [31] to switch the connected 1-P loads from one phase to another based on an algorithm with a minimum count of loads adjustment.

To highlight the originality of the proposed algorithm, a brief description of the literature is presented in Table 1, based on four main characteristics: The network type, the location of PLB operation, the used algorithm, and the operation mode. Other papers from the literature indeed solve the PLB problem, but they coincide with those presented in Table 1 . The objective functions refer to the minimization of unbalance factor at the pillar level or supply point (electric distribution substation).

Table 1. A comparative state-of-the-art between proposed method and the literature.

\begin{tabular}{|c|c|c|c|c|c|c|c|}
\hline $\begin{array}{l}\text { Number of } \\
\text { Reference }\end{array}$ & \multicolumn{2}{|c|}{ Type of Network } & \multicolumn{2}{|c|}{ Location of PLB } & $\begin{array}{c}\text { Type of } \\
\text { Algorithm }\end{array}$ & \multicolumn{2}{|c|}{ Operation Mode } \\
\hline$[5,17,28]$ & Yes & No & No & Yes & Metaheuristic & No & Yes \\
\hline$[6,21,24]$ & No & Yes & No & No & Experimental & No & Yes \\
\hline$[12,13]$ & No & Yes & Yes & No & Metaheuristic & No & Yes \\
\hline$[14,29]$ & No & Yes & Yes & No & Experimental & Yes & No \\
\hline$[15,16]$ & No & Yes & No & Yes & Metaheuristic & No & Yes \\
\hline$[18,32]$ & No & No & No & Yes & Heuristic & No & Yes \\
\hline$[19,20]$ & Yes & No & Yes & No & Heuristic & No & Yes \\
\hline
\end{tabular}

Regardless of the algorithm used and the locations (networks) proposed for the PLB process, each consumer should have a smart phase load balancing system (SPLBS) integrated in the SMS, containing a smart meter and an automatic phase load balancing device (APBD) [27], see Figure 2.

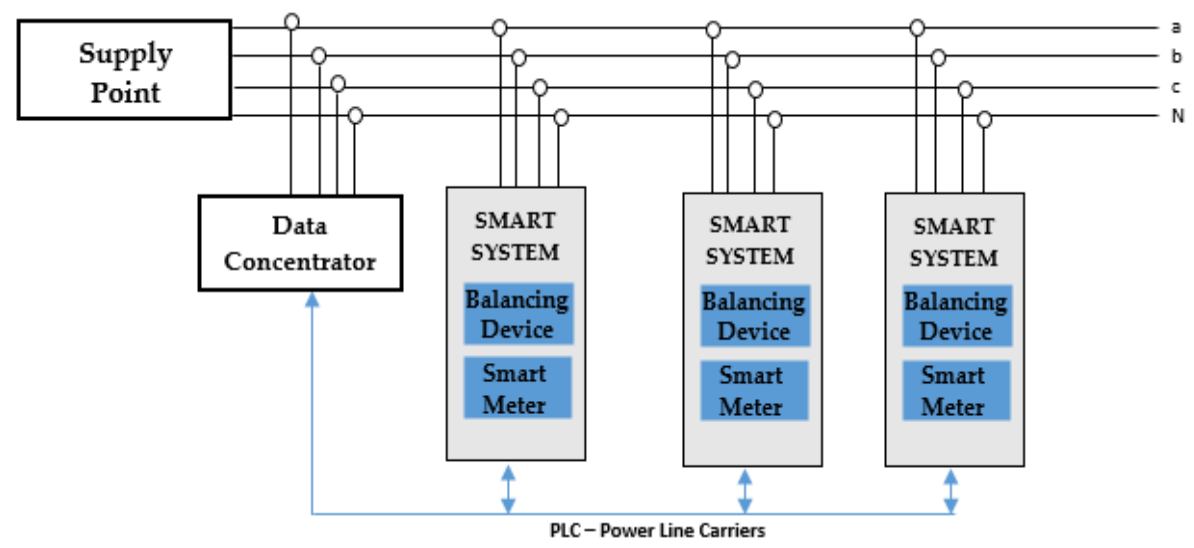

Figure 2. The structure of a smart phase load balancing system (SPLBS) installed at the consumers integrated in the smart metering system (SMS). 
Currently, the technical solution developed by the producers is available to be implemented by the DNOs in the EDN with a high unbalanced degree [33,34]. The solution will be introduced by the DNOs only on basis of a feasibility analysis to justify the investment.

The system contains the following main components: data concentrators, smart phase load balancing systems (SPLBS) placed to the consumers integrated into the SMS, and communication lines. The real-time data communication occurs through power line communication (PLC) wiring from the SPLBS to data concentrators and through various communication channels from the data concentrators to a central database. The use of open standard communication protocols plays a very important role in connecting SPLBS to the data concentrators. Such an approach avoids the massive investment in equipment that is not interoperable and cannot log or generate errors in the data transmission when purchased from different suppliers [35].

The analysis should identify in each stage the associated cost to implement the PLB. The main stages refer to the identification of a feasible technology, the planning of assembly at consumers, the commissioning of the system, the integration in the SMS, testing the communication with data concentrator from the supply point, and the maintenance plan [27].

Compared to the approaches from the literature, the proposed algorithm has the following advantages:

- It can be implemented in the EDNs with hybrid structures of the consumption points (switchable and non-switchable 1-P consumers). The three-phase (3-P) consumers, having identical loadings on the three phases, are not considered in the algorithm, belonging to the non-switchable consumers' category.

- It can work in both operation modes (real-time and off-line), uploading information from different databases of the DNO. The consumers' characteristics (connecting pillar, allocated phase, consumption sector and class, integration in the SMS, identification number of the meter) are extracted based on the identification number of the supply point. The value of consumption and operating status of phase load balancing device (PLBD) are uploaded from the database of the SMS if the meter is integrated, or from the typical load profiles (TLPs) database if the consumer has a standard energy meter (non-integrated in the SMS).

- The convergence is rapid because of the fast recognition of the EDN topology with the help of a structure vectors-based algorithm. The optimal solutions for PLB are found at the level of each pillar such that the global solution obtained for the level of the supply point will be also optimal.

The paper has a structure organized as follows: Section 2 details the stages of the proposed PLB algorithm, accompanied by the implementation procedure. Section 3 presents the results obtained in the case of a real EDN belonging a DNO from the north-eastern of Romania and a comparison with other three algorithms to demonstrate the accuracy of the proposed algorithm. Section 4 highlights the conclusions and the future works.

\section{The Proposed PLB Algorithm}

The proposed algorithm can be implemented at the level of data concentrator from the supply point (electric distribution substation) to work in the real-time mode or to the decision-making central level (DMCL) of DNO for the off-line work mode helping to identify the EDNs with a high unbalanced degree and to determine the optimal solutions to decrease it. The real-time implementation in the soft architecture of the data concentrator from the supply point (SP) involves the installation of a SPLBS at the level of each consumer, as indicated in Figure 2. Also, the algorithm can be implemented in the EDN with standard and smart meters.

The PLB algorithm has the following steps: 


\section{Step 1. Identification of topology for the EDN.}

The topology is identified using a two structure vectors-based algorithm [36]. The algorithm leads to the systematization of the topology, grouping the branches into vicinity levels relative to the supply point (the electric distribution substation). For an EDN with 9 nodes and 8 branches, the branches are grouped in three vicinity levels, starting from the supply point (SP): Level $1-1$ branch (B2); Level 2-2 branches (B3 and B4), and Level 3-5 branches (B5, B6, B7, B8, and B9), see Figure 3. The recognition of each branch is based on the input and end nodes (pillars), being numbered relative to the end node. The input and end nodes of branches are recorded in the vectors $B_{i}$ and $B_{e}$ considered as input data of the algorithm.

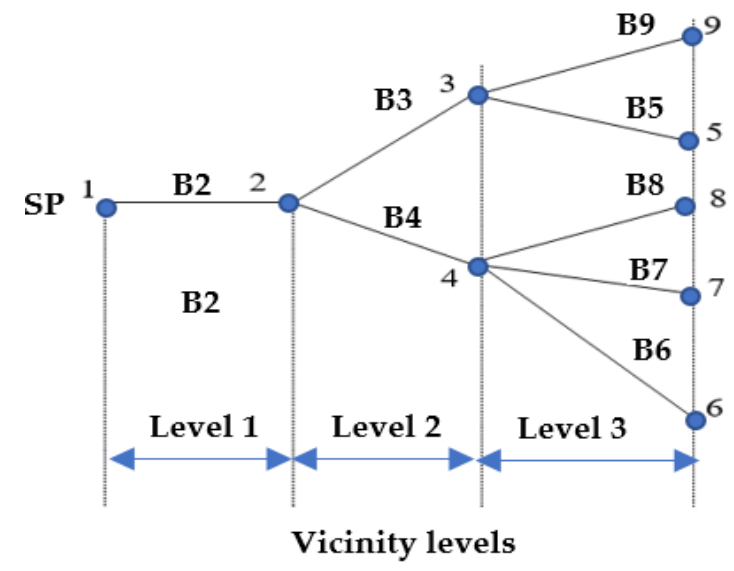

Figure 3. Grouping the branches into vicinity levels.

Considering these aspects, the topology of the EDN can be described using two integer vectors, TV1 and TV2. The vector TV1 contains the number of branches from each vicinity level and the vector TV2 includes all branches in the order of the vicinity levels. The elements of vectors TV1 and TV2 are presented in Table 2.

Table 2. The elements of topology vectors.

\begin{tabular}{cccc}
\hline TV1 & L1 & L2 & L3 \\
\hline TV2 & B1 & B2, B3 & B5, B6, B7, B8, B9 \\
\hline
\end{tabular}

\section{Step 2. Upload the input data sequence}

The algorithm uploads from the database of the DNO a data sequence that is stored in the input vectors. This input data sequence is formed from the following fields, see Figure 4:

- Supply point: Each electric distribution substation has an identification number that allows the algorithm to allocate correct data from the database to all consumers supplied from this point.

- Connecting pillar: The connecting pillar is recorded in the database to identify the position of each consumer in the network. Also, this information is very important in the calculus of a steady-state regime to evaluate the performance of the PLB measure through reducing the power/energy losses and improving the voltage level at the consumers. The vector associated with this field is noted with $C P$, having the size $\left(N_{C} \times 1\right)$, where $N_{C}$ represents the total number of consumers from the EDN.

- Branching Phase: Each 1-P consumer is allocated by the DNO at one of the phases $p h=\{a, b, c\}$, and the 3-P consumers are connected at all three phases $p h=\{a, b, c\}$. The records regarding this information are found in the vector $P B$ with the size $\left(N_{C} \times 1\right)$. 
- Consumption Sector. The information is used to assign the consumer to the following consumption sectors: domestic, non-domestic, commercial, and industrial. The records for this information have the identification numbers from 1 to 4 : 1 (domestic), 2 (non-domestic), 3 (commercial), and 4 (industrial) included in the vector $C S$ with the size $\left(N_{C} \times 1\right)$.

- Consumption class. More consumption classes are allocated to each consumption sector by the DNO. As an example, a Romanian DNO has a classification in five consumption classes for consumers from the domestic sector [36]: < $400 \mathrm{kWh}$ (first class), range [400 kWh, $1250 \mathrm{kWh}$ ] (second class), range [1250 kWh, $2500 \mathrm{kWh]} \mathrm{(third} \mathrm{class),} \mathrm{range} \mathrm{[2500} \mathrm{kWh,} 3500 \mathrm{kWh}$ ] (the fourth class), and range [2500 kWh, $3500 \mathrm{kWh}$ ] (the fifth class). This information is loaded in the vector $C C$, having the size $\left(N_{C} \times 1\right)$.

- Integration in SMS. Currently, not all consumers from the LV distribution networks are integrated into the smart metering system. In this case, the value 1 (if it is integrated) and 0 (otherwise) will be recorded in the database. If the meter is integrated into the SMS, it can communicate to the central system information about the currents or active and reactive powers, which will record them in the database (see Figure 5).

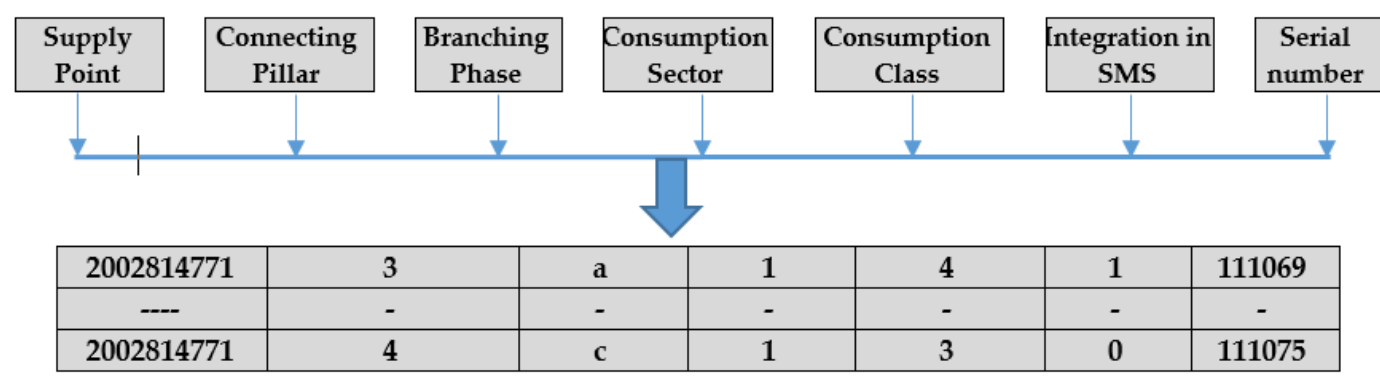

Figure 4. The input data sequence of the algorithm.

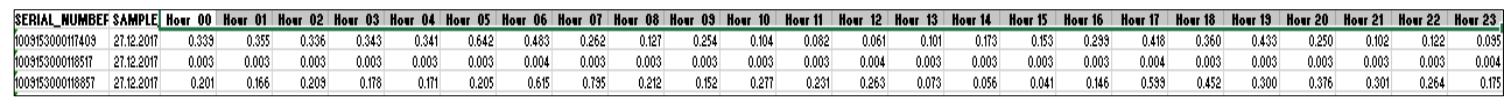

Figure 5. The sequence of the power actives recorded in the database.

If the consumer has a PLBD, then the central system will communicate both its operating status and connection phase. Thus, it will be classified by the algorithm in the category of switchable consumers, recording the value 1 in the database. Otherwise, even if the consumer integrated into the SMS and PLBD is faulty (value is 0), or has a standard meter, it cannot be allocated on other phase and will be classified in the set of non-switchable consumers, recording the value 0 in the database. The algorithm will record these values in the vectors INT (for integration mode) and BS (for the PBLD status), having the size $\left(N_{C} \times 1\right)$. Also, for the non-switchable consumers because of the missing data from the consumption point, the algorithm will use the hourly values from the typical load profiles (TLPs) allocated in function by Consumption Sector (vector CS) and Consumption class (vector CC).

Concerning the TLPs, these are defined by the DNO to all consumers which are not integrated in the SMS and are determined for each consumption sector (domestic, non-domestic, commercial, and industrial) having common characteristics regarding the consumption classes, days (weekend or working), and seasons (springer, summer, autumn, or winter). Finally, each consumer will have an assigned TLP, depending on the above characteristics. The profiling process to obtain the TLPs is presented in [36].

Even if these TLPs are known, the DNOs cannot implement the proposed algorithm in those networks with a high number of non-integrated consumers into the SMS. Within the proposed algorithm, they belong to the category of non-switchable consumers, so that the number of switching solutions will be limited. As the number of non-switchable consumers decreases, the number of 
switching options increases, leading to a solution very close to the optimal solution (in the ideal case, it is equal with 1.00).

The values of the hourly loads for all consumers are recorded in the matrix $I C$, with the size $\left(N_{C} \times H\right)$.

- Serial number. Each consumer is recognized in the database through the serial number of meter installed (smart or standard). The information is recorded in the vector $S N$, having the size $\left(N_{C} \times 1\right)$.

\section{Step 3. The PLB procedure}

The PLB procedure is characterized by a dynamic process which follows the minimization of unbalance degree (as close to 1) at the level of each pillar by allocation to other phases (e.g., phase $a$ on phases $b$ or $c$ ) of the switchable consumers (with SPLBS installed). The procedure is based on the decomposition and coordination of the complex distribution networks. Decomposition considers the division of the distribution network into groups of pillars and to carry out optimization on the pillar level to obtain a minimum unbalance coefficient. At the level of each pillar will be determined the optimal solution considering all combinations between the allocations of the switchable consumers on the phases. The optimal solutions at the level of each pillar are obtained by coordination of the switchable consumers, such that the global optimal solution, represented by the unbalance coefficient at the level of the supply point, will be obtained. In other words, if the balancing solutions are optimal at the level of each pillar, then the global solution at the level of the supply point is also optimal.

To evaluate if an EDN is in an unbalanced regime, an unbalance coefficient is calculated. There are formulas proposed by the IEEE (The Institute of Electrical and Electronics Engineers) and NEMA (The National Equipment Manufacturer's Association) standards [37] for the voltage unbalance. But, there is no widespread agreement for the current unbalance. Thus, the negative and positive sequence components of the current can be used to evaluate the current unbalance [3]. This approach requires the decomposition of the current system into instantaneous positive, negative, and zero sequence components using phasor representation, which is not always possible. Easy evaluation of current unbalance in a node (pillar) of the EDN can be made based on an unbalance coefficient calculated based on the effective values of phase currents [27]. The value of this coefficient must be less than 1.1, agreed by the DNOs.

$$
U C=\frac{1}{3} \cdot\left(\left(\frac{I_{a}}{I_{\text {average }}}\right)^{2}+\left(\frac{I_{b}}{I_{\text {average }}}\right)^{2}+\left(\frac{I_{c}}{I_{\text {average }}}\right)^{2}\right)
$$

where: UC - the unbalance coefficient; $I_{a}, I_{b}, I_{c}$ 一the currents on the phases $a, b$, and $c ; I_{\text {average }}$-the average value of the phase currents.

The mechanism of the proposed algorithm is explained for a particular case with 2 pillars and 5 consumers, see Figure 6 . For the switchable consumers, the initial phase has a yellow color, the optimal phase has a red color, and the phase of non-switchable consumers has a blue color. The optimal phase is the initial phase when the yellow color is missing. It can be observed that one consumer (3) belongs to the non-switchable consumer category, and only two consumers (2 and 5), after applying the algorithm, switched from the phases $\{a, a\}$ to the phases $\{c, b\}$. Consumers 1, 4, and 6 maintained the allocations on the phases $\{b, c, a\}$.

The analysis of the obtained results highlighted that a final value of UC very close by 1 (1.006) can be reached starting from an initial high value (1.636), switching only 2 consumers on other phases. 


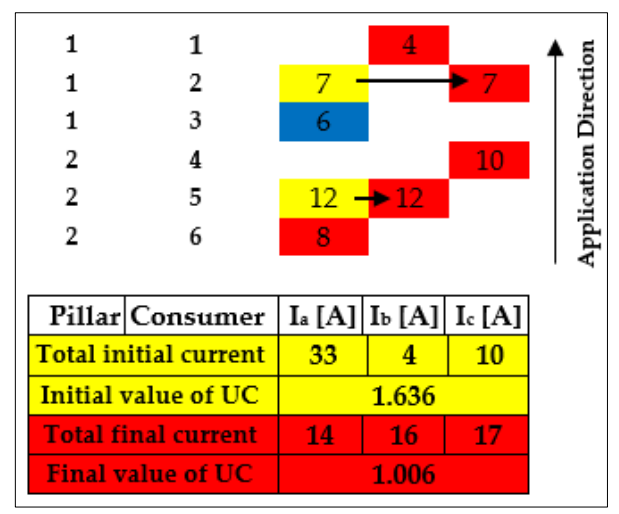

Figure 6. The mechanism of proposed algorithm and the obtained results.

The minimization of unbalance coefficient (UC), at each hour $h=1, \ldots, H$, and each pillar $p=1, \ldots, N p$ represents the objective of the PLB problem:

$$
\min \left(U C^{(p), h}\right), \mathrm{p}=1, \ldots, \mathrm{N}_{\mathrm{p}} ; \mathrm{h}=1, \ldots, \mathrm{H}
$$

where:

$$
\begin{aligned}
& U C^{(p), h}=\frac{1}{3} \cdot\left(\left(\frac{I_{a}^{(p), h}}{I_{\text {average }}^{(p), h}}\right)^{2}+\left(\frac{I_{b}^{(p), h}}{I_{\text {average }}^{(p), h}}\right)^{2}+\left(\frac{I_{c}^{(p), h}}{I_{\text {average }}^{(p), h}}\right)^{2}\right) \\
& I_{\text {average }}^{(p), h}=\frac{1}{3}\left(I_{a}^{(p), h}+I_{b}^{(p), h}+I_{c}^{(p), h}\right) \\
& I_{a}^{(p), h}=I_{a, n s}^{(p), h}+I_{a, s}^{(p), h}+I_{a}^{(d), h} ; \mathrm{p}=1, \ldots, \mathrm{N}_{\mathrm{p}} ; \mathrm{p} \neq \mathrm{d} \\
& I_{b}^{(p), h}=I_{b, n s}^{(p), h}+I_{b, s}^{(p), h}+I_{b}^{(d), h} ; \mathrm{p}=1, \ldots, \mathrm{N}_{\mathrm{p}} ; \mathrm{p} \neq \mathrm{d} \\
& I_{c}^{(p), h}=I_{c, n s}^{(p), h}+I_{c, s}^{(p), h}+I_{c}^{(d), h} ; \mathrm{p}=1, \ldots, \mathrm{N}_{\mathrm{p}} ; \mathrm{p} \neq \mathrm{d} \\
& I_{a, n s}^{(p), h}=\left(\sum_{j=1}^{N_{a, n s}^{(p), h}} I_{a, n s, j}^{(p), h}\right) \\
& I_{b, n s}^{(p), h}=\left(\sum_{k=1}^{N} I_{b, n s}^{(p), h} I_{b, n s, k}^{(p), h}\right) \\
& I_{a, n s}^{(p), h}=\left(\sum_{l=1}^{N_{c, n s}^{(p), h}} I_{c, n s, l}^{(p), h}\right) \\
& I_{a, s}^{(p), h}=\left(\sum_{m=1}^{N_{a, s}^{(p), h}} I_{a, s, m}^{(p), h}\right) \\
& I_{b, s}^{(p), h}=\left(\sum_{n=1}^{N_{b, n s}^{(p), h}} I_{b, s, n}^{(p), h}\right) \\
& I_{c, s}^{(p), h}=\left(\sum_{o=1}^{N_{c, n s}^{(p), h}} I_{c, s, o}^{(p), h}\right)
\end{aligned}
$$




$$
\begin{gathered}
N_{C, n s}^{(p)}=N_{a, n s}^{(p), h}+N_{b, n s}^{(p), h}+N_{c, n s}^{(p), h} \\
N_{C, s}^{(p)}=N_{a, s}^{(p), h}+N_{b, s}^{(p), h}+N_{c, s}^{(p), h} \\
N_{C}^{(p), h}=N_{C, n s}^{(p), h}+N_{C, s}^{(p), h}
\end{gathered}
$$

where: $U C^{(p), h}$ - the unbalance coefficient calculated at the pillar $p$ and hour $h ; I_{a}{ }^{(p), h}, I_{b}{ }^{(p), h}, I_{c}{ }^{(p), h}$ - the currents on the phases $a, b$, and $c$, at the pillar $p$ and hour $h ; I_{\text {average }}{ }^{(p), h}$ - the average value of the phase currents, at the pillar $p$ and hour $h ; I_{a, n s}(p), h, I_{b, n s}(p), h, I_{c, n s}(p), h$ - the total current of the non-switchable consumers on the phases $a, b$, and $c$, at the pillar $p$ and hour $h ; I_{a, s}(p), h, I_{b, s}(p), h, I_{c, s}(p), h$-the total current of the switchable consumers on the phases $a, b$, and $c$, at the pillar $p$ and hour $h ; I_{a, s}{ }^{(d), h}, I_{b, s}{ }^{(d), h}$, $I_{c, s}(d), h$ - the currents on the phases $a, b$, and $c$, at the pillar $d$ (located downstream by pillar $p$ ), and hour $h ; I_{a, n s, j}(p), h$ - the current of the non-switchable consumer $j$ connected on the phase $a$, at the pillar $p$, and hour $h ; I_{b, n s, k}(p), h$ - the current of the non-switchable consumer $k$ connected on the phase $b$, at the pillar $p$, and hour $h ; I_{c, n s, l}(p), h$ - the current of the non-switchable consumer $l$ connected on the phase $c$, at the pillar $p$, and hour $h ; I_{a, s, m}(p), h$ - the current of the switchable consumer $m$ connected on the phase $a$, at the pillar $p$, and hour $h ; I_{b, s, n}(p), h$ — the current of the switchable consumer $n$ connected on the phase $b$, at the pillar $p$, and hour $h ; I_{c, s, o}(p), h$ - the current of the switchable consumer $o$ connected on the phase $c$, at the pillar $p$, and hour $h ; N_{a, n s}(p), h, N_{b, n s}(p), h, N_{c, n s}(p), h$ - the number of the non-switchable consumers connected on the phases $a, b$, and $c$, at the pillar $p$, and hour $h ; N_{a, s}(p), h, N_{b, s}(p), h, N_{c, s}(p), h$ - the number of the switchable consumers connected on the phases $a, b$, and $c$, at the pillar $p$, and hour $h ; N_{C, n s}{ }^{(p), h}$ - the total number of the non-switchable consumers connected at the pillar $p$, and hour $h ; N_{C, s}{ }^{(p), h}$ - the total number of the switchable consumers connected at the pillar $p$, and hour $h ; N_{C}(p), h$ - the total number of the consumers connected at the pillar $p$, and hour $h ; N_{p}$ 一the total number of the pillars; $H$ - the analyzed time period.

The implementation procedure of the mathematical model (2)-(16) is presented in Figure 7a,b, and the details are given in Table 3.

Table 3. The implementation procedure of the proposed phase load balancing (PLB) algorithm.

\section{Steps of PLB Algorithm Based on the Smart Meter Data}

Step 1. Identification of the topology for the EDN based on the vectors TV1 and TV2, built with the vectors $B_{i}$ and $B_{e}$ which contain the input and end nodes (pillars) assigned each branch.

Step 2. Upload the input data sequence from the database of the DNO corresponding to the SP of EDN: Store the information in the vectors: $C P, B P, C S, C C, I N T, B S$, and $S N$.

Determine the number of consumers supplied: $N C=$ length $(S N)$;

Initialize the matrices $I C \in \mathbb{R}^{*(N c \times H)}, I_{a}, I_{b}$, and $I_{\mathcal{C}} \in \mathbb{R}^{*(N p \times H)}$, and $U C \in \mathbb{R}^{*(N p \times H)}$

for each hour $h, h=1 \ldots H$

Set initial consumer index: $i=0$;

while $i \leq N_{c}$

Increase consumer index: $i=i+1$;

if $\operatorname{INT}(i, h)=1$

if $B S(i, h)=1$

Update IC $(i, h)$ with the value recorded on the line $S N(i)$ and column $h$ of the consumption matrix loaded from the SMS; else

Send a warning message to the central system on the failure/missing communication of PLBD to be repaired as soon as possible;

Update IC $(i, h)$ with the assigned value from the TLP depending the records from the vectors CS (i) and CC (i), day (weekend or working), and season (springer, summer, autumn, or winter); else

Update IC $(i, h)$ with the assigned value from the TLP depending the records from the vectors CS (i) and CC (i), day (weekend or working), and season (springer, summer, autumn, or winter); 
Table 3. Cont.

\section{Steps of PLB Algorithm Based on the Smart Meter Data}

Step 3. The PLB sequence at the level of each pillar:

Set initial pillar index: $p=N p$;

while $(p \geq 1)$ and $\left(p \leq N_{p}\right)$

Initialize the vector index;

Find the index corresponding to pillar $p$ in vector $C P$, and store in vector index;

Determine the number of consumers connected at the pillar $p: n_{p}=$ length (index);

Initialize the sums of phase currents corresponding to:

switchable consumers: $I_{a s}=0, I_{b s}=0, I_{c s}=0$;

non-switchable consumers: $I_{a n s}=0, I_{b n s}=0, I_{c n s}=0$;

all consumers: $I_{a p}=0, I_{b p}=0, I_{c p}=0$;

Set initial consumer index: $j=0$;

while $j \leq n_{p}$

Increase consumer index: $j=j+1$;

if $(\operatorname{INT}(\operatorname{index}(j))=0)$ and $(B P($ index $(j))=\{\mathrm{a}\})$

Update sum of current to non-switchable consumers on the phase a:

$I_{\text {ans }}=I_{\text {ans }}+$ IC $($ index $(j))$;

if $B P($ index $(j))=\{b\})$

Update sum of current to non-switchable consumers on the phase $b$ :

$I_{b n s}=I_{b n s}+I C(\operatorname{index}(j))$;

else

Update sum of current to non-switchable consumers on the phase $c$ :

$I_{c n s}=I_{c n s}+I C($ index $(j))$;

if $(\operatorname{INT}($ index $(j))=1)$ and $(B S($ index $(j))=0)$

Changing the category of consumer $j$ from switchable in

non-switchable;

if $(B P($ index $(j))=\{\mathrm{a}\})$

Update sum of current to non-switchable consumers on the phase a:

$I_{\text {ans }}=I_{\text {ans }}+I C($ index $(j))$;

if $B P($ index $(j))=\{b\})$

Update sum of current to non-switchable consumers on

else

the phase $b$ : $I_{b n s}=I_{b n s}+I C($ index $(j))$;

Update sum of current to non-switchable consumers on

the phase $c: I_{c n s}=I_{c n s}+I C($ index $(j))$;

if $(\operatorname{INT}(\operatorname{index}(j))=1)$ and $(B S($ index $(j))=1)$

Assigning the consumer $j$ on each of the three phases:

case Combination 1 -allocation of the consumer $j$ on the phase a

Compute the fictive sum of phase currents to switchable consumers:

$I_{a s f 1}=I_{a s}+I C(\operatorname{index}(j)) ; I_{b s f 1}=I_{b s} ; I_{c s f 1}=I_{c s}$;

Compute the fictive sum of the phase currents to all consumers:

$I_{a p f 1}=I_{a n s}+I_{a s f 1} ; I_{b p f 1}=I_{b n s}+I_{b s f 1} ; I_{c p f 1}=I_{c n s}+I_{c s f 1}$;

Compute the average value of the phase currents, $\mathrm{I}_{\text {average } 1 \text { (rel. (3)) }}$

Compute the $\mathrm{UC}_{1}$ (rel. (2));

case Combination 2 -allocation of the consumer $j$ on the phase $b$

Compute the fictive sum of phase currents to switchable consumers:

$I_{a s f 2}=I_{a s} ; I_{b s f 2}=I_{b s}+I C($ index $(j)) ; I_{c s f 2}=I_{c s}$;

Compute the fictive sum of the phase currents to all consumers:

$I_{a p f 2}=I_{a n s}+I_{a s f 2} ; I_{b p f 2}=I_{b n s}+I_{b s f 2} ; I_{c p f 2}=I_{c n s}+I_{c s f 2} ;$

Compute the average value of the phase currents, $I_{\text {average2, (rel. (3)); }}$

Compute the $\mathrm{UC}_{2}$ (rel. (2)); 
Table 3. Cont.

\section{Steps of PLB Algorithm Based on the Smart Meter Data}

case Combination 3 -allocation of the consumer $j$ on the phase $c$

Compute the fictive sum of phase current to switchable consumers:

$I_{a s f 3}=I_{a s} ; I_{b s f 3}=I_{b s} ; I_{c s f 3}=I_{c s}+\operatorname{IC}(\operatorname{index}(j))$;

Compute the fictive sum of the phase currents of all consumers:

$I_{a p f 3}=I_{a n s}+I_{a s f 3} ; I_{b p f 3}=I_{b n s}+I_{b s f 3} ; I_{c p f 3}=I_{c n s}+I_{c s f 3}$;

Compute the average value of the phase currents, $I_{\text {average } 3}$ (rel. (3));

Compute the $U C_{3}$ (rel. (2));

Determine the minimum value of $U C: \min \left(U C_{1}, U C_{2}, U C_{3}\right)$;

Store the number of combination with $U C_{m i n}, C O_{m i n}$, corresponding to one of the three phase:

if $\mathrm{CO}_{\min }=1$

Update in the vector $P B$ the phase $a: P B($ index $(j))=\{a\}$;

Update the sum of phase currents to switchable consumers:

$I_{a s}=I_{a s f 1} ; I_{b s}=I_{b s f 1} ; I_{c s}=I_{c s f 1}$;

Update the sum of phase currents to all consumers:

$I_{a p}=I_{a p f 1} ; I_{b p}=I_{b p f 1} ; I_{c p}=I_{c p f 1}$;

if $\mathrm{CO}_{\min }=2$

Update in the vector $P B$ the phase $b$ : $P B($ index $(j))=\{b\}$;

Update the sum of phase currents to switchable consumers:

$I_{a s}=I_{a s 2} ; I_{b s}=I_{b s f 2} ; I_{c s}=I_{c s f 2}$;

Update the sum of phase currents to all consumers:

else

$$
I_{a p}=I_{a p f 2} ; I_{b p}=I_{b p f 2} ; I_{c p}=I_{c p f 2}
$$

Update in the vector $P B$ the phase $c: P B($ index $(j))=\{c\}$;

Update the sum of phase currents to switchable consumers:

$I_{a s}=I_{a s 3} ; I_{b s}=I_{b s f 3} ; I_{c s}=I_{c s f 3}$;

Update the sum of phase currents to all consumers:

$$
I_{a p}=I_{a p f 3} ; I_{b p}=I_{b p f 3} ; I_{c p}=I_{c p f 3} ;
$$

Update the value of unbalanced coefficient $U C(p, h)=U C_{\text {min }}$;

Update the value of phase currents $I_{a}(p, h)=I_{a p}, I_{b}(p, h)=I_{b p}$, and $I_{c}(p, h)=I_{c p}$; Decrease pillar index: $p=p-1$;

According with the new allocations from vector $P B$ the central system emits the instructions at each PLBD;

Increase hour index: $h=h+1$;

Print results: $U C, I_{a}, I_{b}, I_{c}$. 


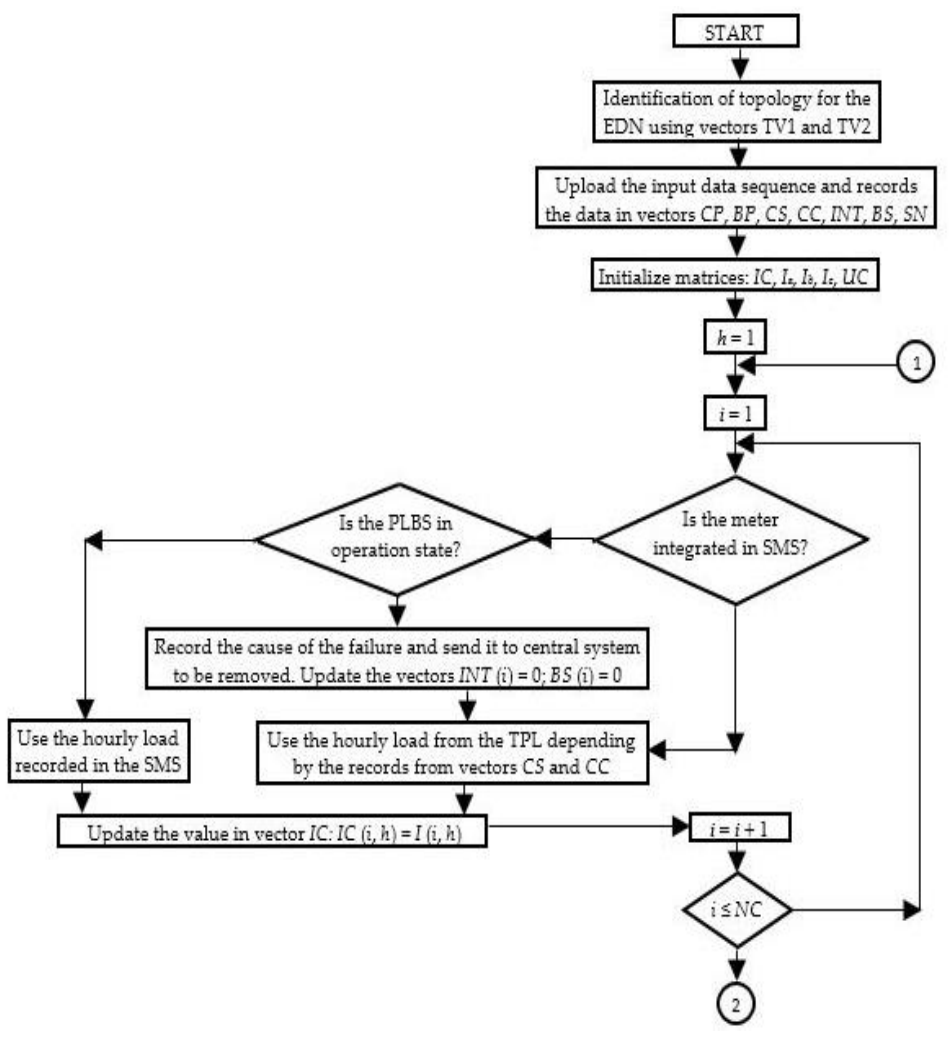

(a)

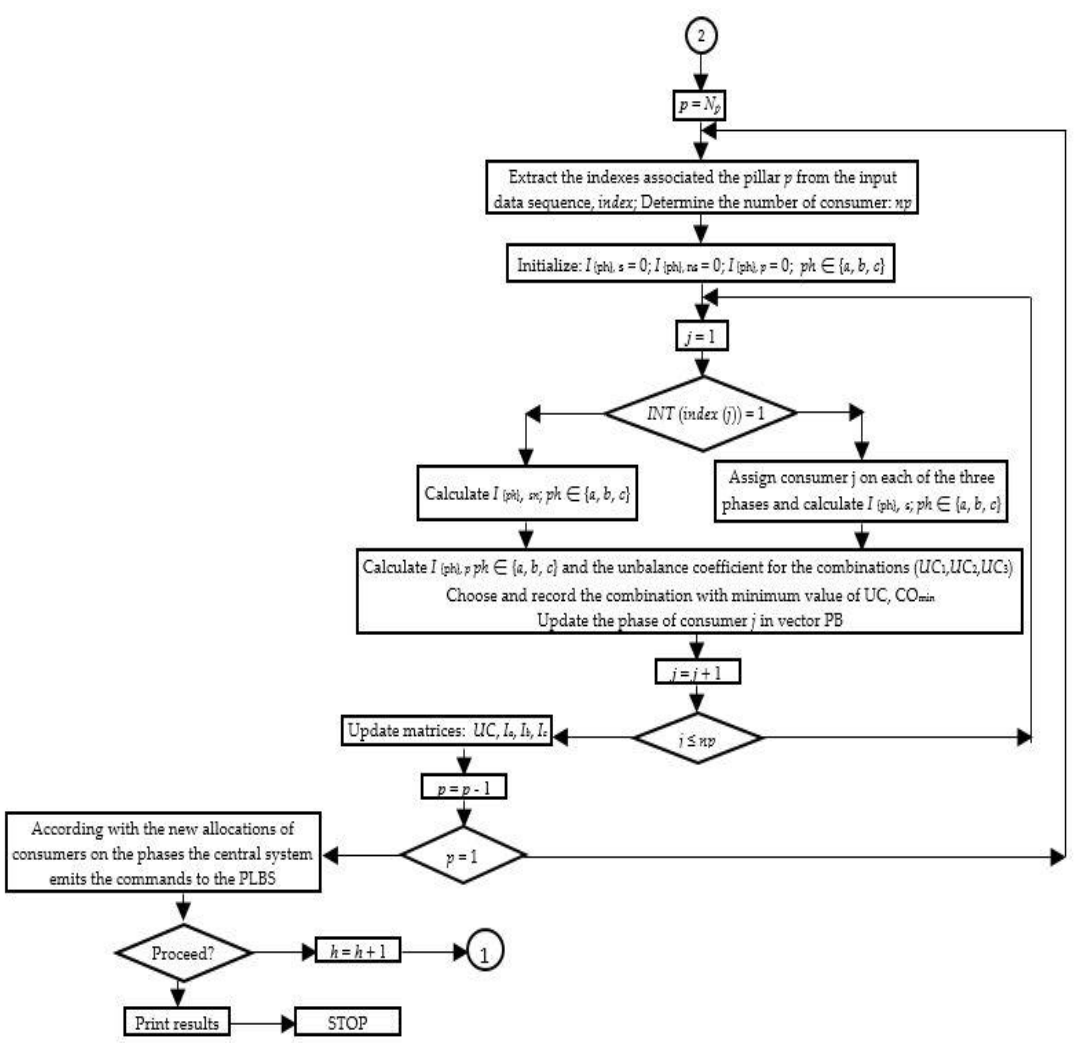

(b)

Figure 7. (a) The flow-chart of the proposed algorithm (the first step-identification of the topology and second step-upload the input data sequence). (b) The flow-chart of the proposed algorithm (the third step-PLB sequence). 


\section{Case Study}

The proposed PLB algorithm was tested in the case of a real LV EDN from a rural area, located in northeastern Romania. The structure of the network is presented in Figure 8. The structure of the network is presented in Figure 8. This network was chosen because of the very complex structure (88 pillars, a total length of $3.52 \mathrm{~km}$, and many lateral branches) and the high number of consumers (163 consumers). Generally, the LV distribution networks have an average length by $1.2 \mathrm{~km}$, with approximately 30 pillars, and an average number of consumers by 60 consumers [38,39]. The values of the characteristics (length, poles, and consumers) of the considered network are about three times higher than the average values. The EDN is supplied from a point (SP), through a power transformer $20 / 0.4 \mathrm{kV}$. The numbering of pillars is real, given by the DNO from this distribution area, beginning with Pillar 8. The distance between two successive pillars is $0.04 \mathrm{~km}$, stipulated in Romanian technical normative [40]. The technical characteristics of the branches are presented in Table 4 , where $\mathrm{r}_{0}$ and $\mathrm{x}_{0}$ represent the specific resistance and reactance. If the reactance is not known, an estimation technique can be used [41].

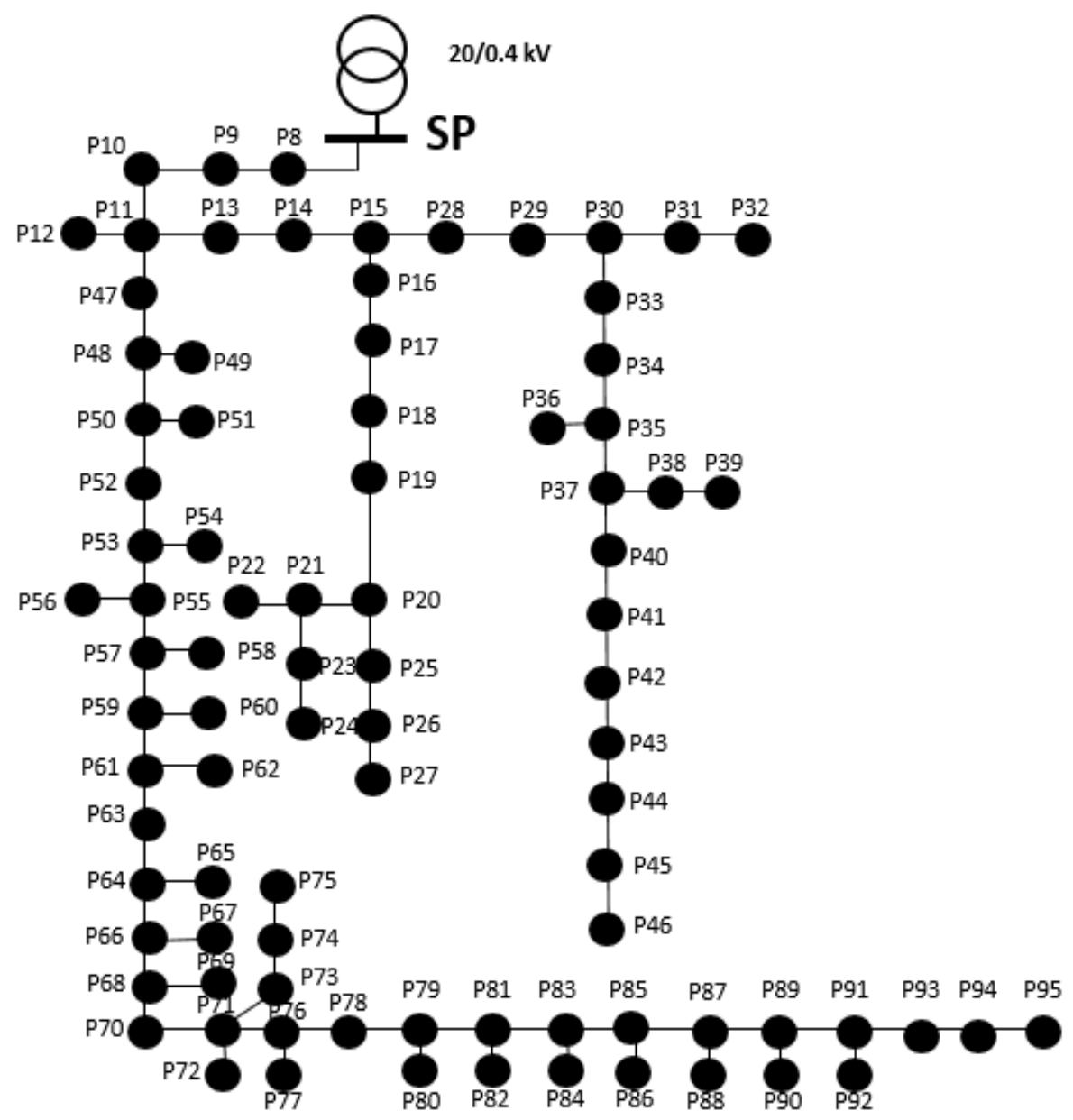

Figure 8. The structure of analyzed electric distribution networks (EDN). 
Table 4. The technical characteristics of the branches.

\begin{tabular}{ccccccc}
\hline Branch & $\begin{array}{c}\text { Type } \\
\text { Conductor }\end{array}$ & $\begin{array}{c}\text { Cross-Section of } \\
\text { Phase Conductors } \\
{\left[\mathbf{m m}^{2}\right]}\end{array}$ & $\begin{array}{c}\text { Cross-Section of } \\
\text { Neutral Conductor } \\
{\left[\mathbf{m m}^{2}\right]}\end{array}$ & $\begin{array}{c}\text { Length } \\
{[\mathbf{k m}]}\end{array}$ & $\begin{array}{c}\mathbf{r}_{\mathbf{0}} \\
{[\mathbf{\Omega} / \mathbf{k m}]}\end{array}$ & $\begin{array}{c}\mathbf{x}_{\mathbf{0}} \\
{[\mathbf{\Omega} / \mathbf{k m}]}\end{array}$ \\
\hline SP-11 & Classic & 50 & 50 & 0.160 & 0.61 & 0.298 \\
$11-15$ & Classic & 50 & 50 & 0.160 & 0.61 & 0.298 \\
$11-95$ & Classic & 50 & 50 & 1.960 & 0.61 & 0.298 \\
$15-27$ & Classic & 35 & 35 & 0.480 & 0.871 & 0.055 \\
$15-39$ & Classic & 35 & 35 & 0.480 & 0.871 & 0.055 \\
$37-46$ & Classic & 25 & 25 & 0.280 & 1.235 & 0.319 \\
& & 50 & 50 & 2.280 & 0.61 & 0.298 \\
& \multirow{2}{*}{ Total } & 35 & 35 & 0.960 & 0.871 & 0.055 \\
& & 25 & 25 & 0.280 & 1.235 & 0.319 \\
\end{tabular}

From the database of the DNO, the information about the characteristics of the consumers from this EDN based on the identification number of the SP was uploaded. The format of the input data was presented in Section 2, see Figure 4. The characteristics of the consumers are presented synthetically in Table 5. Detailed information regarding the connected pillars, the branching phase, and the consumption sector are given in Table A1 from Appendix A.

Table 5. Synthesis on the characteristics of the consumers from the analyzed EDN.

\begin{tabular}{cccccccccc}
\hline Consumer' Type & \multicolumn{4}{c}{ Initial Phase } & \multicolumn{4}{c}{ Consumption SECTOR } \\
\hline 1-P & 3-P & a & b & c & abc & I & II & III & IV \\
\hline 161 & 2 & 42 & 72 & 47 & 2 & 161 & 2 & - & - \\
\hline
\end{tabular}

It can be observed that the vast majority of consumers (98.8\%) have a 1-P branching with the following initial allocation: $25.8 \%$ on phase $a, 44.2 \%$ on phase $b$, and $28.8 \%$ on phase $c$. Only $1.2 \%$ of the consumers have 3-P branching. Regarding the consumption sector, $98.8 \%$ of the consumers belong to the domestic sector, and only $1.2 \%$ are from the non-domestic sector.

From all consumers, 114 1-P consumers, representing 70.8\%, are integrated into the SMS with the possibility to have PLBD installed. They will be considered from the switchable consumers' category in our algorithm. The algorithm imports for each consumer $i, i=1, \ldots, N_{c}$, according to the serial number of meter recorded in the vector $S N$, the hourly load from the database of SMS for the analyzed period $H$. In our case study, the period $H$ corresponds to a winter working day with hourly records $h, h=1, \ldots, 24$, see the supplementary file which contains the active and reactive power profiles. The other 47 1-P consumers are considered as non-switchable consumers due to the standard meters, non-integrated in the SMS. For these consumers, the algorithm uses TLPs according to the information stored in the vectors CS, associated with the consumption sector, and CC, associated with the consumption class.

The phase currents $\left(I_{a}, I_{b}\right.$ and $I_{c}$ ) and neutral current $\left(I_{0}\right)$ in the SP (on the $0.4 \mathrm{kV}$ side) were determined considering all load profiles, using the calculations of steady-state regime, see Table 6 and Figure 9). The used algorithm is an improved version of the forward/backward sweep-based algorithm, developed in [36], to calculate the steady-state regimes to three-phase LV distribution networks in the balanced and unbalanced regime. 
Table 6. The currents in the conductors of the first branch, SP-Pillar 8, initial case.

\begin{tabular}{cccccc}
\hline Hour & $\boldsymbol{I}_{\boldsymbol{a}}[\mathbf{A}]$ & $\boldsymbol{I}_{\boldsymbol{b}}[\mathbf{A}]$ & $\boldsymbol{I}_{\boldsymbol{c}}[\mathbf{A}]$ & $\boldsymbol{I}_{\mathbf{0}}[\mathbf{A}]$ & $\boldsymbol{U} \boldsymbol{C}$ \\
\hline 1 & 14.77 & 48.71 & 19.47 & 31.84 & 1.29 \\
2 & 14.01 & 46.55 & 18.64 & 30.49 & 1.30 \\
3 & 13.24 & 43.81 & 17.73 & 28.58 & 1.29 \\
4 & 13.36 & 44.40 & 17.45 & 29.20 & 1.30 \\
5 & 13.55 & 43.94 & 17.99 & 28.43 & 1.28 \\
6 & 12.38 & 36.47 & 16.98 & 22.15 & 1.23 \\
7 & 16.73 & 41.58 & 19.49 & 23.59 & 1.18 \\
8 & 19.53 & 45.17 & 20.93 & 24.97 & 1.17 \\
9 & 19.69 & 49.91 & 21.88 & 29.18 & 1.20 \\
10 & 18.05 & 53.57 & 21.70 & 33.83 & 1.26 \\
11 & 19.21 & 61.57 & 23.16 & 40.52 & 1.30 \\
12 & 17.44 & 58.17 & 20.53 & 39.28 & 1.33 \\
13 & 17.94 & 61.76 & 21.40 & 42.20 & 1.35 \\
14 & 17.87 & 60.11 & 22.35 & 40.18 & 1.32 \\
15 & 17.91 & 61.07 & 22.21 & 41.18 & 1.33 \\
16 & 15.99 & 54.16 & 21.22 & 35.84 & 1.31 \\
17 & 18.38 & 61.07 & 22.53 & 40.77 & 1.32 \\
18 & 21.55 & 66.87 & 25.80 & 43.34 & 1.29 \\
19 & 21.31 & 59.27 & 25.14 & 36.19 & 1.23 \\
20 & 21.27 & 51.86 & 23.77 & 29.41 & 1.18 \\
21 & 25.66 & 58.78 & 27.08 & 32.43 & 1.17 \\
22 & 27.69 & 68.53 & 31.57 & 39.04 & 1.19 \\
23 & 24.83 & 69.17 & 30.67 & 41.72 & 1.22 \\
24 & 17.12 & 53.18 & 23.17 & 33.45 & 1.26 \\
\hline & & & & &
\end{tabular}

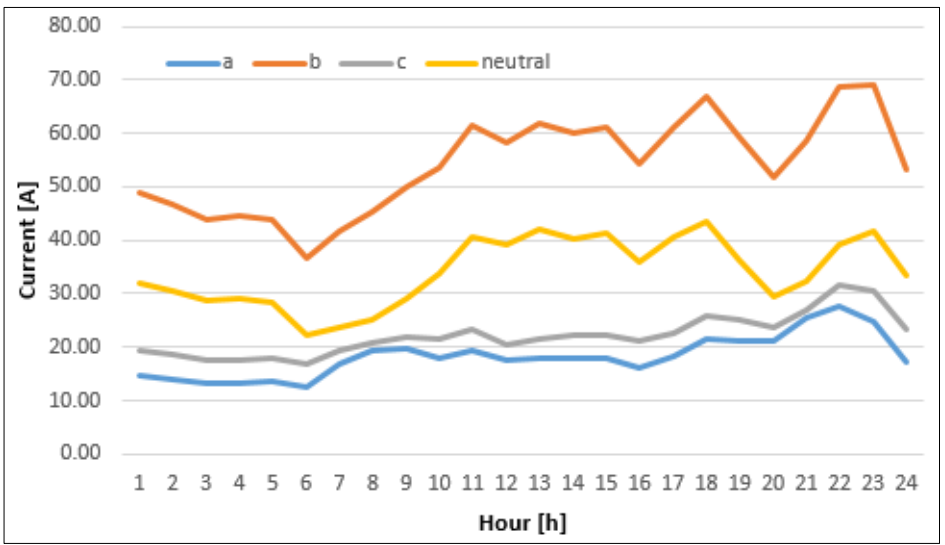

Figure 9. The currents in the conductors of the first branch, SP-Pillar 8, initial case.

The analysis of the obtained results highlights a high difference between the phase currents and an important current in the neutral conductor (exceeds the current on the phases $a$ and $b$ ), which leads to an unbalanced degree beyond the threshold (1.1) imposed by the DNO. The UC is in the range $[1.17,1.35]$, having an average value of 1.26 .

Also, the current unbalance leads to higher power/energy losses because of current flows in the neutral conductor and a significant voltage unbalance, as shown in Table 7 and Figure 10. The losses in the neutral conductor represent an important percent (37\%) of the total energy losses such that the PLB measure must be implemented. 
Table 7. The energy losses calculated in the initial case, [kWh].

\begin{tabular}{|c|c|c|c|c|c|c|c|c|c|}
\hline \multirow{2}{*}{ Hour } & \multicolumn{4}{|c|}{ Main Conductors } & \multicolumn{4}{|c|}{ Branching Conductors } & \multirow{2}{*}{ Total } \\
\hline & $\mathbf{a}$ & $\mathbf{b}$ & c & Neutral & $\mathbf{a}$ & b & c & Neutral & \\
\hline 1 & 0.03 & 0.54 & 0.11 & 0.43 & 0.003 & 0.014 & 0.001 & 0.011 & 1.14 \\
\hline 2 & 0.03 & 0.49 & 0.10 & 0.39 & 0.003 & 0.013 & 0.001 & 0.011 & 1.04 \\
\hline 3 & 0.02 & 0.43 & 0.09 & 0.35 & 0.002 & 0.011 & 0.001 & 0.009 & 0.92 \\
\hline 4 & 0.02 & 0.44 & 0.09 & 0.35 & 0.002 & 0.012 & 0.001 & 0.010 & 0.93 \\
\hline 5 & 0.02 & 0.44 & 0.09 & 0.35 & 0.002 & 0.011 & 0.001 & 0.010 & 0.93 \\
\hline 6 & 0.02 & 0.31 & 0.08 & 0.25 & 0.002 & 0.006 & 0.001 & 0.006 & 0.67 \\
\hline 7 & 0.04 & 0.41 & 0.11 & 0.32 & 0.005 & 0.007 & 0.001 & 0.008 & 0.90 \\
\hline 8 & 0.05 & 0.50 & 0.12 & 0.38 & 0.007 & 0.009 & 0.001 & 0.011 & 1.08 \\
\hline 9 & 0.05 & 0.59 & 0.14 & 0.46 & 0.007 & 0.012 & 0.001 & 0.013 & 1.27 \\
\hline 10 & 0.04 & 0.66 & 0.13 & 0.52 & 0.005 & 0.017 & 0.001 & 0.015 & 1.40 \\
\hline 11 & 0.05 & 0.87 & 0.15 & 0.68 & 0.006 & 0.025 & 0.001 & 0.021 & 1.81 \\
\hline 12 & 0.04 & 0.77 & 0.12 & 0.60 & 0.005 & 0.025 & 0.001 & 0.020 & 1.58 \\
\hline 13 & 0.04 & 0.86 & 0.13 & 0.68 & 0.005 & 0.029 & 0.001 & 0.023 & 1.77 \\
\hline 14 & 0.04 & 0.82 & 0.14 & 0.65 & 0.005 & 0.025 & 0.001 & 0.020 & 1.71 \\
\hline 15 & 0.04 & 0.85 & 0.14 & 0.67 & 0.005 & 0.026 & 0.001 & 0.021 & 1.76 \\
\hline 16 & 0.04 & 0.67 & 0.13 & 0.53 & 0.004 & 0.019 & 0.001 & 0.015 & 1.40 \\
\hline 17 & 0.05 & 0.85 & 0.15 & 0.67 & 0.005 & 0.026 & 0.001 & 0.021 & 1.76 \\
\hline 18 & 0.06 & 1.04 & 0.19 & 0.82 & 0.007 & 0.028 & 0.002 & 0.024 & 2.17 \\
\hline 19 & 0.06 & 0.84 & 0.18 & 0.66 & 0.007 & 0.017 & 0.002 & 0.017 & 1.78 \\
\hline 20 & 0.06 & 0.66 & 0.16 & 0.51 & 0.007 & 0.011 & 0.001 & 0.013 & 1.43 \\
\hline 21 & 0.09 & 0.87 & 0.21 & 0.68 & 0.012 & 0.014 & 0.002 & 0.018 & 1.89 \\
\hline 22 & 0.10 & 1.18 & 0.29 & 0.93 & 0.012 & 0.019 & 0.002 & 0.022 & 2.55 \\
\hline 23 & 0.08 & 1.17 & 0.27 & 0.93 & 0.009 & 0.021 & 0.002 & 0.021 & 2.51 \\
\hline 24 & 0.04 & 0.66 & 0.15 & 0.53 & 0.004 & 0.014 & 0.001 & 0.012 & 1.42 \\
\hline Total & 1.13 & 16.93 & 3.48 & 13.34 & 0.130 & 0.408 & 0.028 & 0.370 & 35.81 \\
\hline
\end{tabular}

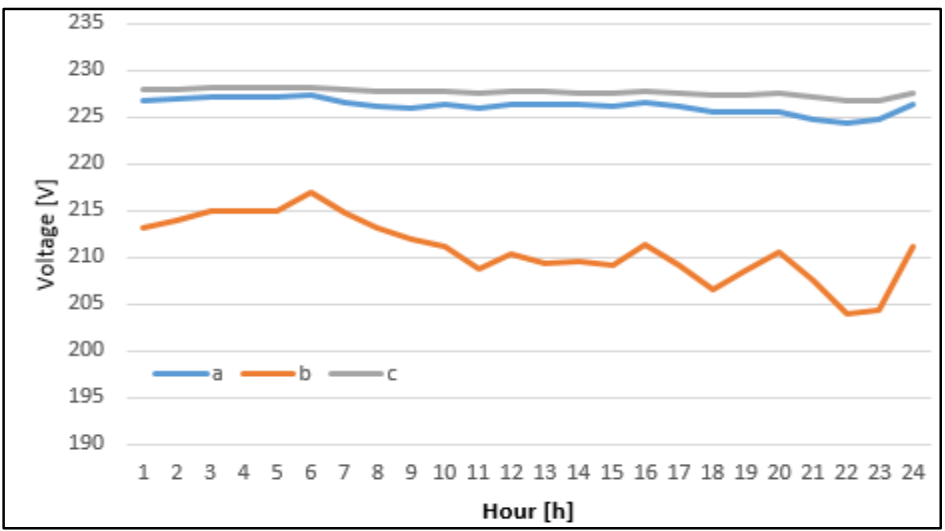

Figure 10. Exemplification of the voltage unbalance at the farthest pillar (P95).

After the application of the proposed algorithm at each hour $h=1, \ldots, 24$, the current unbalance was significantly reduced, see Table 8 . The average value of $U C$ decreased at 1.0017. It can be observed that the current in the neutral conductor decreased with $94 \%$, from the average value of $34.08 \mathrm{~A}$ at $2.07 \mathrm{~A}$. This aspect is highlighted in Figure 11. The effects are felt at the level of power/energy losses, see Table 9, and the voltage quality, see Figure 12. 
Table 8. The currents in the conductors of the first branch, SP-Pillar 8, the proposed algorithm.

\begin{tabular}{cccccc}
\hline Hour & $\boldsymbol{I}_{\boldsymbol{a}}[\mathbf{A}]$ & $\boldsymbol{I}_{\boldsymbol{b}}[\mathbf{A}]$ & $\boldsymbol{I}_{\boldsymbol{c}}[\mathbf{A}]$ & $\boldsymbol{I}_{\mathbf{0}}[\mathbf{A}]$ & $\boldsymbol{U} \boldsymbol{C}$ \\
\hline $\mathbf{1}$ & 27.56 & 27.50 & 27.82 & 0.30 & 1.0000 \\
$\mathbf{2}$ & 26.25 & 26.53 & 26.37 & 0.24 & 1.0000 \\
$\mathbf{3}$ & 24.88 & 25.03 & 24.82 & 0.19 & 1.0000 \\
$\mathbf{4}$ & 25.29 & 24.88 & 24.99 & 0.36 & 1.0000 \\
$\mathbf{5}$ & 25.22 & 25.01 & 25.21 & 0.21 & 1.0000 \\
$\mathbf{6}$ & 21.47 & 22.69 & 21.65 & 1.14 & 1.0006 \\
$\mathbf{7}$ & 24.77 & 24.68 & 28.31 & 3.58 & 1.0042 \\
$\mathbf{8}$ & 31.90 & 26.76 & 26.93 & 5.06 & 1.0070 \\
$\mathbf{9}$ & 28.83 & 29.06 & 33.54 & 4.59 & 1.0050 \\
$\mathbf{1 0}$ & 30.66 & 30.78 & 31.81 & 1.10 & 1.0003 \\
$\mathbf{1 1}$ & 34.76 & 34.55 & 34.53 & 0.22 & 1.0000 \\
$\mathbf{1 2}$ & 32.61 & 31.65 & 31.78 & 0.91 & 1.0002 \\
$\mathbf{1 3}$ & 33.25 & 34.50 & 33.23 & 1.26 & 1.0003 \\
$\mathbf{1 4}$ & 33.91 & 33.04 & 33.29 & 0.77 & 1.0001 \\
$\mathbf{1 5}$ & 33.49 & 34.20 & 33.40 & 0.76 & 1.0001 \\
$\mathbf{1 6}$ & 30.88 & 30.23 & 30.18 & 0.68 & 1.0001 \\
$\mathbf{1 7}$ & 33.72 & 34.38 & 33.77 & 0.64 & 1.0001 \\
$\mathbf{1 8}$ & 38.43 & 37.96 & 37.71 & 0.63 & 1.0001 \\
$\mathbf{1 9}$ & 37.69 & 34.07 & 33.87 & 3.72 & 1.0025 \\
$\mathbf{2 0}$ & 30.67 & 30.70 & 35.48 & 4.79 & 1.0049 \\
$\mathbf{2 1}$ & 34.87 & 41.56 & 35.03 & 6.61 & 1.0070 \\
$\mathbf{2 2}$ & 40.63 & 46.86 & 40.21 & 6.46 & 1.0051 \\
$\mathbf{2 3}$ & 39.94 & 40.25 & 44.37 & 4.29 & 1.0024 \\
$\mathbf{2 4}$ & 31.96 & 30.73 & 30.71 & 1.24 & 1.0004 \\
\hline
\end{tabular}

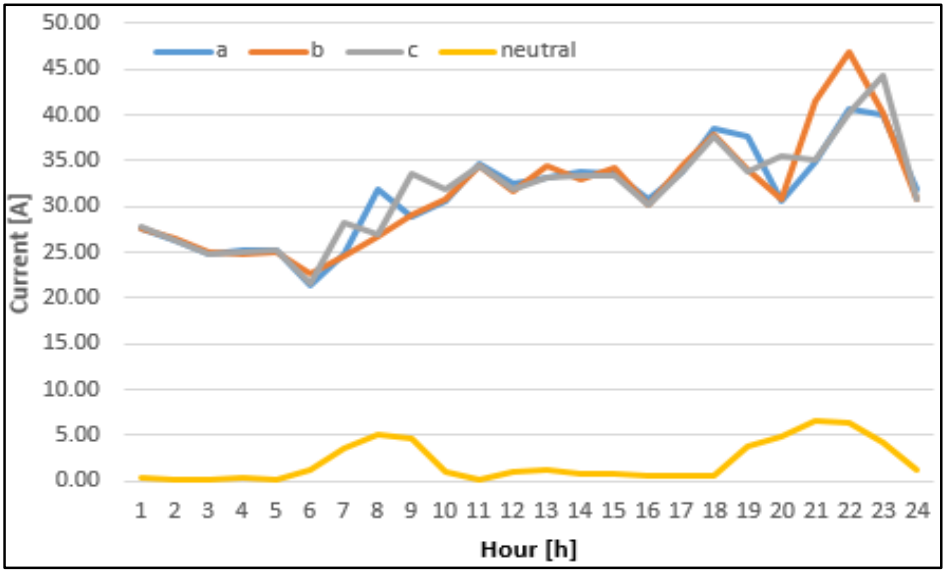

Figure 11. The currents in the conductors of the first branch, SP-Pillar 8, with the proposed algorithm.

The results were compared with other algorithms to emphasize the accuracy of the smart meter data-based proposed algorithm (SMD): from heuristic (the minimum count of loads adjustment (MCLA) algorithm [32]) and metaheuristic (particle swarm optimization (PSO) algorithm [28] and genetic algorithm (AG) [17]) categories. The computational times needed to obtain the solution are presented in Table 10 for each algorithm. The algorithms with a Matlab implementation were run on a computer Intel Core i5, 3.10 GHz, 4GB RAM, WIN 10 64-bit operating system. 
Table 9. The energy losses calculated with the data obtained using the proposed algorithm, [kWh].

\begin{tabular}{|c|c|c|c|c|c|c|c|c|c|}
\hline \multirow{2}{*}{ Hour } & \multicolumn{4}{|c|}{ Main Conductors } & \multicolumn{4}{|c|}{ Branching Conductors } & \multirow{2}{*}{ Total } \\
\hline & $\mathbf{a}$ & $\mathbf{b}$ & c & Neutral & $\mathbf{a}$ & $\mathbf{b}$ & c & Neutral & \\
\hline 1 & 0.12 & 0.13 & 0.14 & 0.01 & 0.00 & 0.01 & 0.01 & 0.01 & 0.43 \\
\hline 2 & 0.11 & 0.13 & 0.12 & 0.01 & 0.00 & 0.01 & 0.01 & 0.01 & 0.39 \\
\hline 3 & 0.10 & 0.12 & 0.10 & 0.01 & 0.00 & 0.01 & 0.00 & 0.01 & 0.35 \\
\hline 4 & 0.12 & 0.10 & 0.10 & 0.01 & 0.01 & 0.01 & 0.00 & 0.01 & 0.35 \\
\hline 5 & 0.11 & 0.11 & 0.10 & 0.01 & 0.01 & 0.00 & 0.00 & 0.01 & 0.35 \\
\hline 6 & 0.08 & 0.08 & 0.08 & 0.00 & 0.00 & 0.00 & 0.00 & 0.01 & 0.26 \\
\hline 7 & 0.11 & 0.11 & 0.13 & 0.01 & 0.00 & 0.00 & 0.01 & 0.01 & 0.37 \\
\hline 8 & 0.17 & 0.12 & 0.13 & 0.01 & 0.01 & 0.00 & 0.00 & 0.01 & 0.45 \\
\hline 9 & 0.17 & 0.13 & 0.18 & 0.01 & 0.01 & 0.00 & 0.01 & 0.01 & 0.52 \\
\hline 10 & 0.15 & 0.17 & 0.17 & 0.01 & 0.01 & 0.01 & 0.01 & 0.01 & 0.54 \\
\hline 11 & 0.22 & 0.20 & 0.20 & 0.01 & 0.01 & 0.01 & 0.01 & 0.02 & 0.68 \\
\hline 12 & 0.19 & 0.16 & 0.17 & 0.01 & 0.01 & 0.01 & 0.01 & 0.02 & 0.59 \\
\hline 13 & 0.17 & 0.23 & 0.19 & 0.02 & 0.01 & 0.02 & 0.01 & 0.02 & 0.66 \\
\hline 14 & 0.21 & 0.19 & 0.18 & 0.01 & 0.01 & 0.01 & 0.01 & 0.02 & 0.64 \\
\hline 15 & 0.17 & 0.22 & 0.19 & 0.01 & 0.01 & 0.01 & 0.01 & 0.02 & 0.65 \\
\hline 16 & 0.17 & 0.15 & 0.16 & 0.01 & 0.01 & 0.01 & 0.01 & 0.01 & 0.52 \\
\hline 17 & 0.17 & 0.22 & 0.20 & 0.01 & 0.01 & 0.01 & 0.01 & 0.02 & 0.66 \\
\hline 18 & 0.23 & 0.27 & 0.24 & 0.01 & 0.01 & 0.01 & 0.01 & 0.02 & 0.82 \\
\hline 19 & 0.22 & 0.22 & 0.19 & 0.01 & 0.01 & 0.01 & 0.01 & 0.02 & 0.69 \\
\hline 20 & 0.16 & 0.18 & 0.20 & 0.01 & 0.00 & 0.01 & 0.01 & 0.01 & 0.58 \\
\hline 21 & 0.21 & 0.29 & 0.22 & 0.02 & 0.00 & 0.02 & 0.01 & 0.02 & 0.78 \\
\hline 22 & 0.28 & 0.35 & 0.32 & 0.02 & 0.00 & 0.02 & 0.01 & 0.02 & 1.01 \\
\hline 23 & 0.30 & 0.28 & 0.32 & 0.01 & 0.01 & 0.01 & 0.01 & 0.02 & 0.96 \\
\hline 24 & 0.16 & 0.18 & 0.16 & 0.01 & 0.00 & 0.01 & 0.01 & 0.01 & 0.54 \\
\hline Total & 4.09 & 4.34 & 4.18 & 0.26 & 0.15 & 0.20 & 0.19 & 0.36 & 13.76 \\
\hline
\end{tabular}

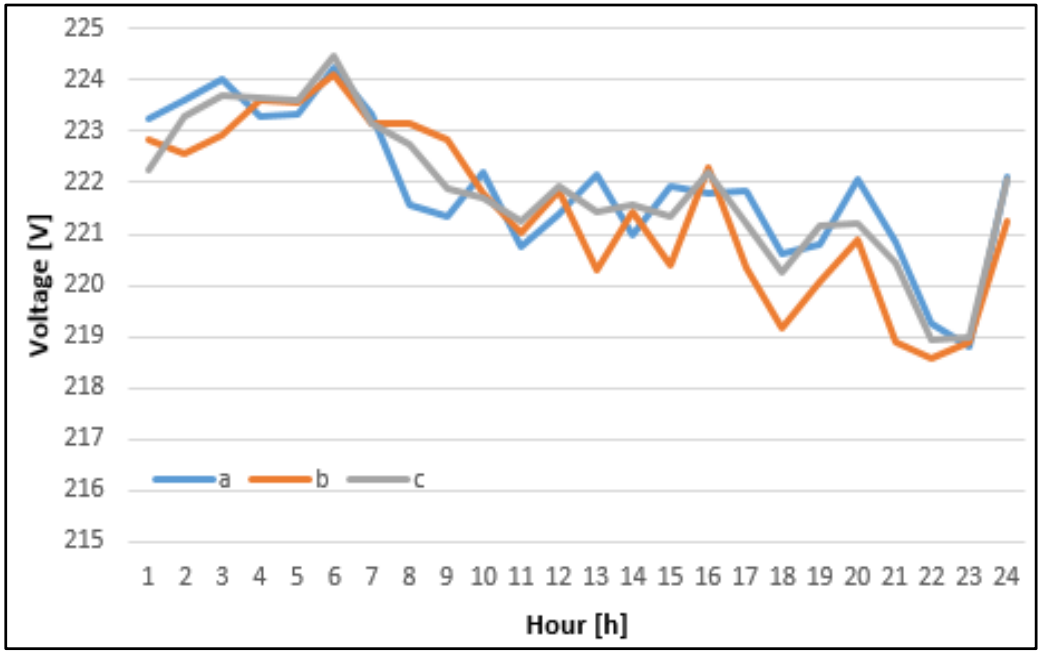

Figure 12. Improvement of voltage quality at the farthest pillar (P95), after applying the proposed algorithm.

Table 10. Comparison between the computational times.

\begin{tabular}{ccc}
\hline No. & Algorithm & Computational Times [Seconds] \\
\hline 1 & SMD (Proposed) & 1.26 \\
2 & MCLA & 0.58 \\
3 & PSO & 348 \\
4 & GA & 291 \\
\hline
\end{tabular}


The values from the table correspond to $24 \mathrm{~h}$. It can be observed that the lowest values were obtained for the heuristic methods (SMD and MCLA) and higher values for the metaheuristic methods (PSO and GA). Even if the computational time of MCLA is lower than SMD, this does not guarantee that effects will be better in the evaluation of the UC coefficient, the current in the neutral conductor (and implicit on the energy losses), or the voltage at the level of each pillar.

Regarding the UC coefficient, the obtained value with the proposed algorithm is identical with AG (1.0017) at the SP level, being smaller than in the case of MCLA and PSO, as shown in Figure 13.

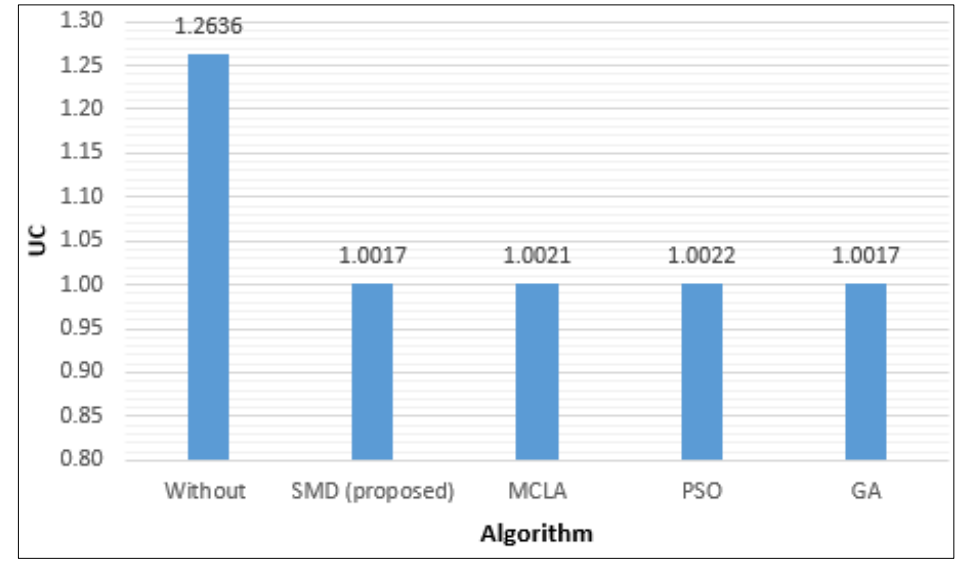

Figure 13. Comparison between the average values of $U C$ at the SP level, calculated with different algorithms.

Also, a comparison with the mathematical programming models, proposed by Arias et al. in [4] and Zhu et al. in [42], was done considering the UC coefficient. The UC coefficient was reduced from 1.17 to 1.07 (a reduction with 9.4\%) using the Branch and Bound algorithm (BBA), proposed in [4], in the case of a test radial network without lateral branches. The mixed-integer programming (MIP) led at a reduction of the UC coefficient from 1.086 to 1.005 (a reduction with $8 \%$ ) for a test network with 6 nodes [42]. The values are indicated in Table 11.

Table 11. Comparison with the linear programming models.

\begin{tabular}{cccccc}
\hline \multirow{2}{*}{ No. } & \multirow{2}{*}{ Algorithm } & Characteristics of EDN & UC $_{\text {initial }}$ & UC $_{\text {final }}$ & $\begin{array}{c}\text { Improvement } \\
{[\%]}\end{array}$ \\
\hline 1 & SMD (Proposed) & real/complex/88 nodes/163 consumers & 1.26 & 1.0017 & 25.8 \\
2 & BBA & fictive/radial without lateral branches/51 consumers & 1.17 & 1.07 & 9.4 \\
3 & MIP & fictive/radial with 2 lateral branches/6 nodes & 1.086 & 1.005 & 8.0 \\
\hline
\end{tabular}

The results confirm the advantages of the proposed algorithm compared with the mathematical programming algorithms. Also, the accuracy of the SMD algorithm was demonstrated in the case of a real complex EDN, compared with the other two algorithms, which were tested using fictive EDNs, with simple topologies (radial).

To highlight the effects on the decrease of the current in the neutral conductor (and implicit on the energy losses) and on improving the voltage quality at the level of each pillar, the steady-state regimes were calculated, having as input data the load matrices obtained with each algorithm (SDM, MCLA, PSO, and GA). The average value of the current in the neutral conductor, on the first branch, is shown in Figure 14, for each algorithm. It can be observed that the smallest value was obtained by applying the proposed algorithm (2.07 A), with $22.7 \%$ better than GA. 


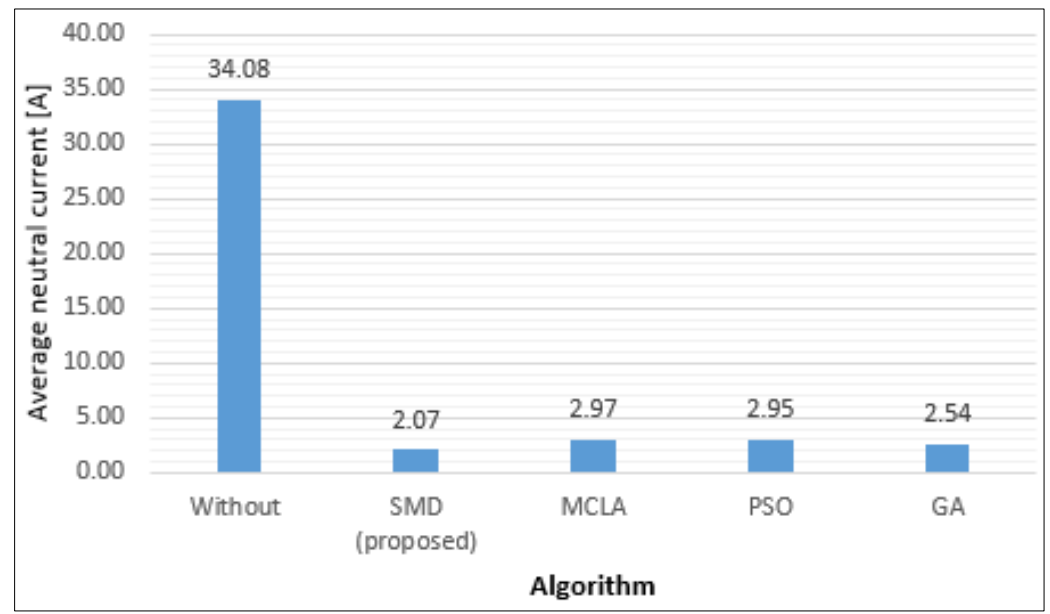

Figure 14. Comparison between the average values of neutral current in the first branch, SP-Pillar 8 , calculated with different algorithms.

Regarding the energy losses, Table 12 presents the values calculated on the phase and neutral conductors on the branching and main conductors. The analysis of the results indicates smaller energy losses in the case of the proposed algorithm compared to the other algorithms, as shown in Table 12 and Figure 15 . The energy losses decreased by $0.20 \%$, more than in the case of AG. The difference from the MCLA algorithm is higher, with $19.01 \%$.

Table 12. Comparison between the energy losses calculated with different algorithms, [kWh].

\begin{tabular}{cccccccccccc}
\hline \multirow{2}{*}{ Algorithm } & \multicolumn{4}{c}{ Main Conductors } & \multicolumn{3}{c}{ Branching Conductors } & \multicolumn{3}{c}{ Total } & $\begin{array}{c}\delta \boldsymbol{\Delta} \mathbf{W} \\
{[\%]}\end{array}$ \\
\cline { 2 - 9 } & $\mathbf{a}$ & $\mathbf{b}$ & $\mathbf{c}$ & Neutral & $\mathbf{a}$ & $\mathbf{b}$ & $\mathbf{c}$ & Neutral & & - \\
\hline Without & 1.13 & 16.93 & 3.48 & 13.34 & 0.13 & 0.41 & 0.03 & 0.37 & 35.81 & - \\
SMD (proposed) & 4.09 & 4.34 & 4.18 & 0.26 & 0.15 & 0.20 & 0.19 & 0.36 & 13.76 & 61.57 \\
MCLA & 4.14 & 6.23 & 4.98 & 4.32 & 0.33 & 0.05 & 0.16 & 0.36 & 20.57 & 42.56 \\
PSO & 4.44 & 4.43 & 3.77 & 0.32 & 0.23 & 0.17 & 0.15 & 0.36 & 13.86 & 61.30 \\
GA & 3.66 & 4.62 & 4.50 & 0.51 & 0.14 & 0.19 & 0.21 & 0.36 & 14.19 & 60.37 \\
\hline
\end{tabular}

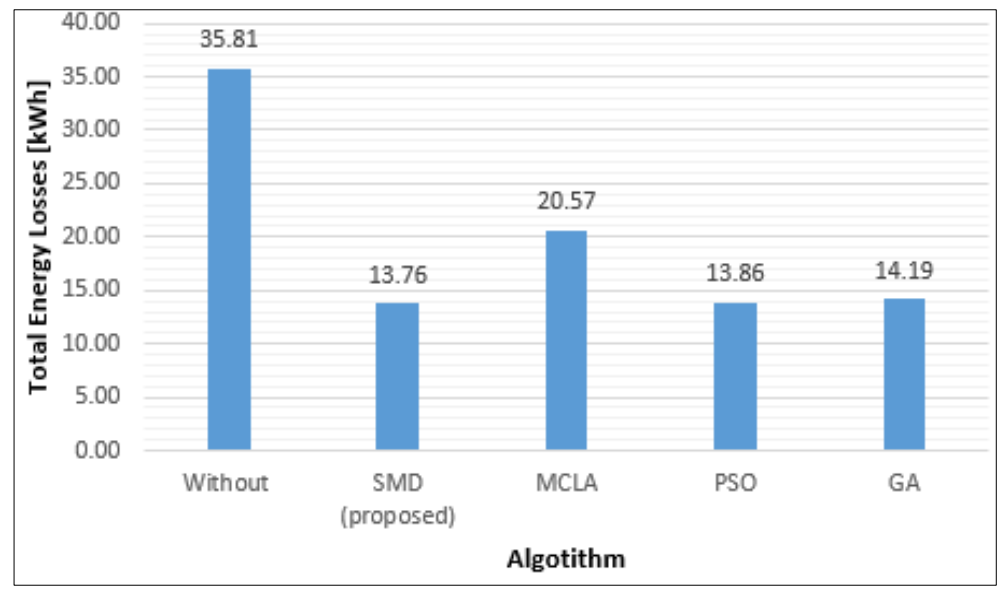

Figure 15. Comparison between the total energy losses, calculated with different algorithms. 
Also, the saving-energy $(\delta \Delta W)$, given in percent, are indicated in Table 12 . The calculation relation is the following:

$$
\delta \Delta W=\left|\frac{\Delta W_{\text {initial }}-\Delta W_{\text {algorithm }}}{\Delta W_{\text {initial }}}\right| \cdot 100,[\%]
$$

where algorithm is SMD, MCLA, PSO, and GA.

The voltage quality was evaluated at the level of the farthest pillar (P95), and the results are presented in Table 13. The minimum values are highlighted with bold to be easily identified in the analysis. It can be observed that the phase voltages are between the admissible limits (rated voltage $\pm 10 \%$, where the rated voltage is $230 \mathrm{~V}$ ). Small differences between the phase voltages, in the range $[0.13 \mathrm{~V}, 0.36 \mathrm{~V}]$, were obtained in the case of the proposed algorithm, with an improvement of value on phase $b$ of $14.58 \mathrm{~V}(7.15 \%)$. The biggest differences, in the range [5.59 V, $12.9 \mathrm{~V}]$, were obtained in the case of the MCLA algorithm.

Table 13. The minimum value of the phase voltages at the level of the farthest pillar (P95).

\begin{tabular}{cccc}
\hline \multirow{2}{*}{ Algorithm } & \multicolumn{3}{c}{ Phase } \\
\cline { 2 - 4 } & $\mathbf{a}$ & $\mathbf{b}$ & $\mathbf{c}$ \\
\hline Without & 224.33 & $\mathbf{2 0 4 . 0 0}$ & 226.71 \\
SMD (proposed) & 218.81 & $\mathbf{2 1 8 . 5 8}$ & 218.94 \\
MCLA & 218.90 & $\mathbf{2 1 1 . 5 9}$ & 224.49 \\
PSO & $\mathbf{2 1 8 . 1 9}$ & 219.03 & 218.55 \\
GA & 219.41 & $\mathbf{2 1 7 . 2 8}$ & 219.07 \\
\hline
\end{tabular}

The detailed results for each algorithm are presented in Tables A2-A5 from Appendix B.

\section{Conclusions}

In the paper, a PLB algorithm was proposed having the following advantages: It can be implemented in the EDNs with hybrid structures of the consumption points (switchable and non-switchable consumers); it can work in both operation modes (real-time and off-line), uploading information from different databases of the DNO which contain the consumers' characteristics, real loads of the consumers integrated into the SMS, and loads from the TLPs for the consumers non-integrated in the SMS; the convergence is rapid because of the fast recognition of EDN topology with the help of a structure vectors based-algorithm.

The testing of the algorithm was made in a real rural EDN from the northeastern region of Romania, having a hybrid structure of the consumption points (114 1-P consumers $(70.8 \%)$ are integrated into the SMS with the possibility to have SPLBS, the other consumers having standard meter). The obtained results were analyzed and compared with other algorithms from the heuristic category (minimum count of loads adjustment (MCLA) algorithm) and the metaheuristic category (particle swarm optimization (PSO) and genetic algorithm (AG)).

The best performances were recorded for the proposed algorithm, obtaining the smallest value of the unbalance coefficient (1.0017), in comparison with MCLA (1.0022) and PSO (1.0021) algorithms. The same value (1.0017) was also obtained in the case of AG. The average value of the current in the neutral conductor decreased with $94 \%$ from the average value of $34.08 \mathrm{~A}$ (initial case) at $2.07 \mathrm{~A}$. This value is smaller with $22.70 \%$ than AG, $42.51 \%$ than PSO, and $43.47 \%$ than MCLA. The energy losses decreased with $61.75 \%$ compared to the initial case using the data obtained with the proposed algorithm. This value is smaller by $0.20 \%$ than AG, $0.27 \%$ than PSO, and $19.01 \%$ than MCLA.

The proposed solution can be introduced by the DNOs to ensure the transition toward the smart grids, but only on the basis of a feasibility analysis, to justify the investment. Also, the DNOs must take into account that the proposed algorithm cannot have very high efficiency in networks with many not integrated consumers into the SMS, for which the TLPs must be associated. Within the proposed algorithm, they belong to the category of non-switchable consumers, so that the number of switching 
options will be limited. The transition process should be mainly implemented in the "hot" areas where there are EDNs without or with small number of non-switchable consumers, leading to a solution very close to the optimal solution (in the ideal case, it is equal with 1.00).

The authors work now at an improved variant of the proposed algorithm, which considers the weight of each switchable consumer at the unbalance degree. The main objective is the determination of the optimal number of PLBD, which minimizes the unbalance coefficient and the investment costs.

Supplementary Materials: The following are available online at http://www.mdpi.com/2227-7390/8/4/549/s1.

Author Contributions: G.G. proposed the implementation methodology, mathematical modeling, validation, and writing - original draft preparation B.-C.N. implemented the software, data curation, and validation; C.B. and I.T. improved the methodology, performed simulations, and writing; M.G. performed simulations, and reviewed the manuscript. All authors discussed the results and have agreed with the structure of the paper. All authors have read and agreed to the published version of the manuscript.

Funding: This research received no external funding.

Conflicts of Interest: The authors declare no conflict of interest.

\section{Nomenclature}

$0 \quad$ Neutral conductor

1-P Single-phase consumer

3-P Three-phase consumer

EDN Electric distribution network

LV Low voltage

TLP Typical load profile

DNO Distribution network operator

SMS Smart metering system

SMD Smart meter data

PLB Phase load balancing

PLC Power-line communication

SCADA Supervisory control and data acquisition

APLBD Automatic phase load balancing device

SPLBS Smart phase load balancing system

DMCL Decision-making central level

PSO Particle swarm optimization

AG Genetic algorithm

MCLA Minimum count of loads adjustment

$H \quad$ The analyzed time period, [hours]

$B_{i} \quad$ Vector of the input nodes of branches

$B_{j} \quad$ Vector of the end nodes of branches

$a, b, c \quad$ The phases of the EDN

$a b c \quad 3-P$ consumer in the input data files

\{ph\} The set of phases $\{a, b, c\}$

TV1 Topology vector containing the number of branches from each vicinity level

TV2 Topology vector containing the branches placed in the order of the vicinity levels

SP Supply Point

$N_{C} \quad$ The total number of consumers from the EDN

$C P \quad$ Vector of the connected pillars, size $\left(N_{C} \times 1\right)$

$P B \quad$ Vector of the branching phase, size $\left(N_{C} \times 1\right)$

CS Vector of the consumption sector of the consumers, size $\left(N_{C} \times 1\right)$ 
CC Vector of the consumption class of the consumers from a certain consumption sector, size $\left(N_{C} \times 1\right)$

INT Vector of the integration mode in the SMS, size $\left(N_{C} \times 1\right)$

BS Vector of the PLBD status, size $\left(N_{C} \times 1\right)$

IC Vector of the hourly loads for all consumers, size $\left(N_{C} \times H\right)$

SN Vector of the serial numbers corresponding the smart meters, size $\left(N_{C} \times 1\right)$

$\mathrm{r}_{0} \quad$ Specific resistance, $[\Omega / \mathrm{km}]$

$\mathrm{x}_{0} \quad$ Specific reactance, $[\Omega / \mathrm{km}]$

UC The unbalance coefficient

$I_{a}, I_{b}, I_{c} \quad$ The currents on the phases $a, b$, and $c,[\mathrm{~A}]$

Iaverage The average value of the phase currents, [A]

$h \quad$ The current hour $(h=1, \ldots, H)$

$N_{p} \quad$ The number of pillars from the EDN

$p \quad$ The analyzed current pillar $\left(p=1, \ldots, N_{p}\right)$

$d \quad$ Pillar located downstream by pillar $p$

$U C^{(p), h} \quad$ The unbalance coefficient calculated at the pillar $p$ and hour $h$

index Vector of the indices corresponding to pillar $p$ in vector $C P$

$I_{a}(p), h \quad$ The current on the phase $a$, at the pillar $p$ and hour $h,[\mathrm{~A}]$

The current on the phase $b$, at the pillar $p$ and hour $h$, [A]

$I_{a, n s}(p), h$

The current on the phase $c$, at the pillar $p$ and hour $h$, [A]

$I_{b, n s}(p), h$

$I_{c, n s}(p), h$

The total current of the non-switchable consumers on the phase $a$, pillar $p$ and hour $h$, [A]

The total current of the non-switchable consumers on the phase $b$, pillar $p$ and hour $h$, [A]

$I_{a, s}(p), h$

$I_{b, s}(p), h$

$I_{c, s}(p), h$

$I_{a}^{(d), h}$

$I_{b, s}(d), h$

$I_{C, S}(d), h$

The total current of the non-switchable consumers on the phase $c$, pillar $p$ and hour $h$, [A]

The total current of the switchable consumers on the phase $a$, pillar $\mathrm{p}$ and hour $h$, [A]

The total current of the switchable consumers on the phase $b$, pillar $\mathrm{p}$ and hour $h$, [A]

The total current of the switchable consumers on the phase $c$, pillar p and hour $h$, [A]

The currents on the phase $a$, pillar $d$, and hour $h$, [A]

The currents on the phase $b$, pillar $d$, and hour $h$, [A]

The currents on the phase $c$, pillar $d$, and hour $h$, [A]

Index of the non-switchable consumer connected on the phase $a$, pillar $p$, and hour $h$

Index of the non-switchable consumer connected on the phase $b$, pillar $p$, and hour $h$

Index of the non-switchable consumer connected on the phase $c$, pillar $p$, and hour $h$

$m$

$n$

Index of the switchable consumer connected on the phase $a$, pillar $p$, and hour $h$

Index of the switchable consumer connected on the phase $b$, pillar $p$, and hour $h$

Index of the switchable consumer connected on the phase $c$, pillar $p$, and hour $h$

$N_{a, n s}(p), h$

$N_{b, n s}(p), h$

The number of the non-switchable consumers connected on the phase $a$, pillar $p$, and hour $h$

$N_{\mathcal{C}, n s}(p), h$

The number of the non-switchable consumers connected on the phase $b$, pillar $p$, and hour $h$

$N_{a, s}(p), h$

The number of the non-switchable consumers connected on the phase $c$, pillar $p$, and hour $h$

$N_{b, s}(p), h$

The number of the switchable consumers connected on the phase $a$, pillar $p$, and hour $h$

$N_{c, s}(p), h$

The number of the switchable consumers connected on the phase $b$, pillar $p$, and hour $h$

$N_{C, n s}(p), h$

The number of the switchable consumers connected on the phases $c$, pillar $p$, and hour $h$

$N_{C, S}(p), h$

The total number of the non-switchable consumers connected at the pillar $p$, and hour $h$

$N_{C}(p), h$

The total number of the switchable consumers connected at the pillar $p$, and hour $h$

$I_{a, n s, j}(p), h$

The total number of the consumers connected at the pillar $p$, and hour $h$

$I_{b, n s, k}(p), h$

The current of the non-switchable consumer $j\left(j=1, \ldots, N_{a, n s}(p), h\right)$, [A]

$I_{c, n s, l}(p), h$

The current of the non-switchable consumer $k\left(k=1, \ldots, N_{b, n s}(p), h\right)$, [A]

$I_{a, s, m}(p), h$

The current of the non-switchable consumer $l\left(l=1, \ldots, N_{c, n s}(p), h\right)$, [A]

$I_{a, s, n}(p), h$

The current of the switchable consumer $m\left(m=1, \ldots, N_{a, s}(p), h\right),[\mathrm{A}]$

$I_{a, s, 0}(p), h$

The current of the switchable consumer $n\left(n=1, \ldots, N_{b, s}{ }^{(p), h}\right)$, [A]

$\delta \Delta W$

The current of the switchable consumer $o\left(o=1, \ldots, N_{c, s}{ }^{(p), h}\right),[\mathrm{A}]$

The percentage error, [\%] 


\section{Appendix A}

Table A1. The allocation on pillar, phase, and the consumption sector.

\begin{tabular}{|c|c|c|c|c|c|c|c|c|c|c|c|c|c|c|c|c|c|}
\hline \multirow[t]{2}{*}{ Pillar } & \multicolumn{2}{|c|}{$\begin{array}{c}\text { Consumer' } \\
\text { Type }\end{array}$} & \multicolumn{3}{|c|}{$\begin{array}{l}\text { Branching } \\
\text { Phase }\end{array}$} & \multicolumn{3}{|c|}{$\begin{array}{c}\text { Consumption } \\
\text { Sector }\end{array}$} & \multirow[t]{2}{*}{ Pillar } & \multicolumn{2}{|c|}{$\begin{array}{l}\text { Consumer' } \\
\text { Type }\end{array}$} & \multicolumn{3}{|c|}{$\begin{array}{c}\text { Branching } \\
\text { Phase }\end{array}$} & \multicolumn{3}{|c|}{$\begin{array}{c}\text { Consumption } \\
\text { Sector }\end{array}$} \\
\hline & 1-P & 3-P & a & $\mathbf{b}$ & c & 1 & 2 & 3 & & $1-P$ & $3-P$ & a & b & c & 1 & 2 & 3 \\
\hline 8 & 2 & - & - & 2 & - & 1 & - & - & 51 & 2 & - & - & 1 & 1 & 1 & - & - \\
\hline 9 & 2 & - & - & 2 & - & 1 & - & - & 52 & 3 & - & - & 3 & - & 1 & - & - \\
\hline 10 & 3 & - & 2 & 1 & - & 1 & - & - & 53 & 1 & - & - & 1 & - & - & 2 & - \\
\hline 11 & 1 & - & - & 1 & - & 1 & - & - & 54 & 6 & - & - & - & 6 & 1 & - & - \\
\hline 12 & 2 & - & - & 2 & - & 1 & - & - & 55 & 2 & - & 1 & 1 & - & 1 & - & - \\
\hline 13 & 1 & - & - & 1 & - & 1 & - & - & 56 & 2 & - & - & 2 & - & 1 & - & - \\
\hline 14 & 2 & - & - & - & 2 & 1 & - & - & 57 & 1 & - & - & 1 & - & 1 & - & - \\
\hline 15 & 2 & - & - & 1 & 1 & 1 & - & - & 58 & 1 & - & 1 & - & - & 1 & - & - \\
\hline 17 & 1 & 1 & 1 & 1 & 1 & 1 & - & - & 59 & 2 & - & - & 2 & - & 1 & - & - \\
\hline 18 & 2 & - & - & - & 2 & 1 & - & - & 60 & 2 & - & 1 & 1 & - & 1 & - & - \\
\hline 19 & 2 & - & 2 & - & - & 1 & - & - & 61 & 1 & - & - & 1 & - & 1 & - & - \\
\hline 20 & 2 & - & 2 & - & - & 1 & - & - & 62 & 1 & - & - & - & 1 & 1 & - & - \\
\hline 21 & 1 & - & 1 & - & - & 1 & - & - & 63 & 2 & - & 2 & - & - & 1 & - & - \\
\hline 22 & 2 & - & 1 & 1 & - & 1 & - & - & 65 & 1 & - & - & 1 & - & 1 & - & - \\
\hline 23 & 2 & - & 2 & - & - & 1 & - & - & 66 & 4 & - & 1 & 3 & - & 1 & - & - \\
\hline 24 & 1 & - & - & - & 1 & 1 & - & - & 67 & 2 & - & - & 2 & - & 1 & - & - \\
\hline 26 & 2 & - & - & - & 2 & 1 & - & - & 68 & 2 & - & - & 2 & - & 1 & - & - \\
\hline 27 & 3 & - & 1 & - & 2 & 1 & - & - & 69 & 2 & - & 1 & 1 & - & 1 & - & - \\
\hline 28 & 2 & - & - & 1 & 1 & 1 & - & - & 70 & 1 & - & - & 1 & - & 1 & - & - \\
\hline 29 & 4 & - & - & 1 & 3 & 1 & - & - & 71 & 1 & - & - & 1 & - & 1 & - & - \\
\hline 30 & 2 & - & - & - & 2 & 1 & - & - & 72 & 1 & - & - & 1 & - & 1 & - & - \\
\hline 31 & 2 & - & - & - & 2 & 1 & - & - & 75 & 2 & - & - & 2 & - & 1 & - & - \\
\hline 32 & 1 & - & - & - & 1 & 1 & - & - & 76 & 2 & - & - & 2 & - & 1 & - & - \\
\hline 33 & 4 & - & - & - & 4 & 1 & - & - & 77 & 2 & - & 1 & 1 & - & 1 & - & - \\
\hline 34 & 5 & - & - & - & 5 & 1 & - & - & 78 & 4 & - & 1 & 3 & - & 1 & - & - \\
\hline 35 & 4 & - & 1 & 1 & 2 & 1 & - & - & 79 & 1 & 1 & 1 & 2 & 1 & 1 & - & - \\
\hline 36 & 1 & - & - & 1 & - & 1 & - & - & 80 & 2 & - & & 2 & - & 1 & - & - \\
\hline 37 & 3 & - & - & - & 3 & 1 & - & - & 82 & 2 & - & - & 2 & - & 1 & - & - \\
\hline 38 & 1 & - & - & - & 1 & 1 & - & - & 83 & 1 & - & 1 & - & - & 1 & - & - \\
\hline 39 & 4 & - & - & 1 & 3 & 1 & - & - & 84 & 2 & - & - & 2 & - & 1 & - & - \\
\hline 40 & 3 & - & - & - & 3 & 1 & - & - & 86 & 1 & - & - & 1 & - & 1 & - & - \\
\hline 41 & 1 & - & - & - & 1 & 1 & - & - & 87 & 2 & - & - & 2 & - & 1 & - & - \\
\hline 42 & 1 & - & - & - & 1 & 1 & - & - & 88 & 1 & - & - & 1 & - & 1 & - & - \\
\hline 43 & 2 & - & - & - & 2 & 1 & - & - & 89 & 2 & - & - & 2 & - & 1 & - & - \\
\hline 44 & 2 & - & - & 1 & 1 & 1 & - & - & 90 & 1 & - & - & 1 & - & 1 & - & - \\
\hline 45 & 4 & - & - & - & 4 & 1 & - & - & 91 & 2 & - & - & 2 & - & 1 & - & - \\
\hline 46 & 2 & - & - & - & 2 & 1 & - & - & 92 & 1 & - & - & 1 & - & 1 & - & - \\
\hline 47 & 3 & - & 1 & 2 & - & 1 & - & - & 93 & 2 & - & - & 2 & - & 1 & - & - \\
\hline 48 & 3 & - & 1 & 2 & - & 1 & 2 & - & 94 & 1 & - & 1 & - & - & 1 & - & - \\
\hline 49 & 2 & - & - & 2 & - & 1 & - & - & 95 & 1 & - & - & 1 & - & 1 & - & - \\
\hline 50 & 1 & - & - & - & 1 & 1 & - & - & & & & & & & & & \\
\hline
\end{tabular}




\section{Appendix B}

Table A2. Comparison between the hourly UC calculated with different algorithms at the SP level.

\begin{tabular}{cccccc}
\hline Hour & Without & SMD (Proposed) & MCLA & PSO & GA \\
\hline $\mathbf{1}$ & 1.2949 & 1.0000 & 1.0001 & 1.0017 & 1.0010 \\
$\mathbf{2}$ & 1.2965 & 1.0000 & 1.0005 & 1.0023 & 1.0009 \\
$\mathbf{3}$ & 1.2923 & 1.0000 & 1.0007 & 1.0024 & 1.0007 \\
$\mathbf{4}$ & 1.3016 & 1.0000 & 1.0012 & 1.0026 & 1.0011 \\
$\mathbf{5}$ & 1.2837 & 1.0000 & 1.0010 & 1.0029 & 1.0007 \\
$\mathbf{6}$ & 1.2265 & 1.0006 & 1.0005 & 1.0023 & 1.0003 \\
$\mathbf{7}$ & 1.1840 & 1.0042 & 1.0017 & 1.0010 & 1.0027 \\
$\mathbf{8}$ & 1.1700 & 1.0070 & 1.0042 & 1.0021 & 1.0046 \\
$\mathbf{9}$ & 1.2036 & 1.0050 & 1.0040 & 1.0004 & 1.0017 \\
$\mathbf{1 0}$ & 1.2630 & 1.0003 & 1.0022 & 1.0007 & 1.0000 \\
$\mathbf{1 1}$ & 1.3041 & 1.0000 & 1.0039 & 1.0018 & 1.0007 \\
$\mathbf{1 2}$ & 1.3339 & 1.0002 & 1.0031 & 1.0029 & 1.0019 \\
$\mathbf{1 3}$ & 1.3485 & 1.0003 & 1.0026 & 1.0040 & 1.0028 \\
$\mathbf{1 4}$ & 1.3209 & 1.0001 & 1.0028 & 1.0028 & 1.0016 \\
$\mathbf{1 5}$ & 1.3313 & 1.0001 & 1.0027 & 1.0031 & 1.0023 \\
$\mathbf{1 6}$ & 1.3078 & 1.0001 & 1.0012 & 1.0030 & 1.0013 \\
$\mathbf{1 7}$ & 1.3198 & 1.0001 & 1.0025 & 1.0030 & 1.0021 \\
$\mathbf{1 8}$ & 1.2881 & 1.0001 & 1.0018 & 1.0010 & 1.0006 \\
$\mathbf{1 9}$ & 1.2344 & 1.0025 & 1.0011 & 1.0001 & 1.0003 \\
$\mathbf{2 0}$ & 1.1843 & 1.0049 & 1.0029 & 1.0025 & 1.0032 \\
$\mathbf{2 1}$ & 1.1691 & 1.0070 & 1.0040 & 1.0053 & 1.0058 \\
$\mathbf{2 2}$ & 1.1867 & 1.0051 & 1.0031 & 1.0028 & 1.0032 \\
$\mathbf{2 3}$ & 1.2241 & 1.0024 & 1.0021 & 1.0007 & 1.0008 \\
$\mathbf{2 4}$ & 1.2562 & 1.0004 & 1.0005 & 1.0008 & 1.0001 \\
\hline
\end{tabular}

Table A3. Comparison between the hourly neutral currents calculated with different algorithms, the first branch (SP-Pillar 8).

\begin{tabular}{cccccc}
\hline Hour & Without & SMD (Proposed) & MCLA & PSO & GA \\
\hline $\mathbf{1}$ & 31.84 & 0.30 & 0.56 & 2.42 & 1.87 \\
$\mathbf{2}$ & 30.49 & 0.24 & 1.23 & 2.68 & 1.72 \\
$\mathbf{3}$ & 28.58 & 0.19 & 1.40 & 2.60 & 1.42 \\
$\mathbf{4}$ & 29.20 & 0.36 & 1.81 & 2.71 & 1.74 \\
$\mathbf{5}$ & 28.43 & 0.21 & 1.67 & 2.85 & 1.39 \\
$\mathbf{6}$ & 22.15 & 1.14 & 1.06 & 2.21 & 0.87 \\
$\mathbf{7}$ & 23.59 & 3.58 & 2.27 & 1.75 & 2.85 \\
$\mathbf{8}$ & 24.97 & 5.06 & 3.90 & 2.79 & 4.10 \\
$\mathbf{9}$ & 29.18 & 4.59 & 4.07 & 1.34 & 2.66 \\
$\mathbf{1 0}$ & 33.83 & 1.10 & 3.11 & 1.70 & 0.30 \\
$\mathbf{1 1}$ & 40.52 & 0.22 & 4.57 & 3.07 & 1.98 \\
$\mathbf{1 2}$ & 39.28 & 0.91 & 3.78 & 3.67 & 2.92 \\
$\mathbf{1 3}$ & 42.20 & 1.26 & 3.67 & 4.49 & 3.80 \\
$\mathbf{1 4}$ & 40.18 & 0.77 & 3.73 & 3.76 & 2.85 \\
$\mathbf{1 5}$ & 41.18 & 0.76 & 3.68 & 3.98 & 3.39 \\
$\mathbf{1 6}$ & 35.84 & 0.68 & 2.19 & 3.52 & 2.34 \\
$\mathbf{1 7}$ & 40.77 & 0.64 & 3.59 & 3.96 & 3.33 \\
$\mathbf{1 8}$ & 43.34 & 0.63 & 3.39 & 2.58 & 1.89 \\
$\mathbf{1 9}$ & 36.19 & 3.72 & 2.49 & 0.74 & 1.37 \\
$\mathbf{2 0}$ & 29.41 & 4.79 & 3.68 & 3.39 & 3.90 \\
$\mathbf{2 1}$ & 32.43 & 6.61 & 4.97 & 5.71 & 6.03 \\
$\mathbf{2 2}$ & 39.04 & 6.46 & 5.02 & 4.75 & 5.12 \\
$\mathbf{2 3}$ & 41.72 & 4.29 & 3.99 & 2.30 & 2.44 \\
$\mathbf{2 4}$ & 33.45 & 1.24 & 1.53 & 1.90 & 0.79 \\
\hline
\end{tabular}


Table A4. Comparison between the hourly power losses calculated with different algorithms, [kWh].

\begin{tabular}{|c|c|c|c|c|c|c|c|c|c|c|c|c|}
\hline \multirow{2}{*}{ Hour } & \multicolumn{3}{|c|}{ SMD (Proposed) } & \multicolumn{3}{|c|}{ MCLA } & \multicolumn{3}{|c|}{ PSO } & \multicolumn{3}{|c|}{ GA } \\
\hline & a & $\mathbf{b}$ & c & $\mathbf{a}$ & $\mathbf{b}$ & c & a & $\mathbf{b}$ & c & a & $\mathbf{b}$ & c \\
\hline 1 & 0.40 & 0.03 & 0.43 & 0.60 & 0.03 & 0.63 & 0.40 & 0.03 & 0.43 & 0.43 & 1.68 & 2.11 \\
\hline 2 & 0.36 & 0.03 & 0.39 & 0.54 & 0.03 & 0.57 & 0.37 & 0.03 & 0.39 & 0.39 & 1.52 & 1.91 \\
\hline 3 & 0.32 & 0.02 & 0.35 & 0.48 & 0.02 & 0.50 & 0.33 & 0.02 & 0.35 & 0.35 & 1.35 & 1.70 \\
\hline 4 & 0.33 & 0.02 & 0.35 & 0.48 & 0.02 & 0.50 & 0.33 & 0.02 & 0.36 & 0.35 & 1.36 & 1.71 \\
\hline 5 & 0.33 & 0.02 & 0.35 & 0.49 & 0.02 & 0.51 & 0.33 & 0.02 & 0.36 & 0.35 & 1.38 & 1.73 \\
\hline 6 & 0.25 & 0.01 & 0.26 & 0.40 & 0.01 & 0.41 & 0.25 & 0.01 & 0.26 & 0.26 & 1.08 & 1.35 \\
\hline 7 & 0.35 & 0.02 & 0.37 & 0.55 & 0.02 & 0.57 & 0.35 & 0.02 & 0.37 & 0.37 & 1.51 & 1.88 \\
\hline 8 & 0.43 & 0.03 & 0.45 & 0.67 & 0.03 & 0.70 & 0.42 & 0.03 & 0.45 & 0.45 & 1.85 & 2.30 \\
\hline 9 & 0.48 & 0.03 & 0.52 & 0.74 & 0.03 & 0.77 & 0.48 & 0.03 & 0.51 & 0.52 & 2.06 & 2.58 \\
\hline 10 & 0.50 & 0.04 & 0.54 & 0.75 & 0.04 & 0.78 & 0.51 & 0.04 & 0.54 & 0.54 & 2.11 & 2.64 \\
\hline 11 & 0.63 & 0.05 & 0.68 & 0.91 & 0.05 & 0.96 & 0.64 & 0.05 & 0.69 & 0.68 & 2.59 & 3.27 \\
\hline 12 & 0.54 & 0.05 & 0.59 & 0.83 & 0.05 & 0.88 & 0.55 & 0.05 & 0.60 & 0.59 & 2.35 & 2.94 \\
\hline 13 & 0.60 & 0.06 & 0.66 & 0.92 & 0.06 & 0.97 & 0.61 & 0.06 & 0.67 & 0.66 & 2.60 & 3.25 \\
\hline 14 & 0.59 & 0.05 & 0.64 & 0.84 & 0.05 & 0.89 & 0.60 & 0.05 & 0.64 & 0.64 & 2.42 & 3.05 \\
\hline 15 & 0.60 & 0.05 & 0.65 & 0.86 & 0.05 & 0.91 & 0.61 & 0.05 & 0.66 & 0.65 & 2.46 & 3.11 \\
\hline 16 & 0.49 & 0.04 & 0.52 & 0.71 & 0.04 & 0.75 & 0.49 & 0.04 & 0.53 & 0.52 & 2.02 & 2.55 \\
\hline 17 & 0.61 & 0.05 & 0.66 & 0.87 & 0.05 & 0.92 & 0.62 & 0.05 & 0.67 & 0.66 & 2.50 & 3.16 \\
\hline 18 & 0.76 & 0.06 & 0.82 & 1.12 & 0.06 & 1.18 & 0.77 & 0.06 & 0.82 & 0.82 & 3.18 & 3.99 \\
\hline 19 & 0.65 & 0.04 & 0.69 & 1.01 & 0.04 & 1.05 & 0.65 & 0.04 & 0.69 & 0.69 & 2.79 & 3.48 \\
\hline 20 & 0.55 & 0.03 & 0.58 & 0.89 & 0.03 & 0.92 & 0.55 & 0.03 & 0.58 & 0.58 & 2.42 & 3.00 \\
\hline 21 & 0.73 & 0.04 & 0.78 & 1.15 & 0.04 & 1.19 & 0.73 & 0.04 & 0.77 & 0.78 & 3.16 & 3.94 \\
\hline 22 & 0.96 & 0.05 & 1.01 & 1.58 & 0.05 & 1.64 & 0.96 & 0.05 & 1.01 & 1.01 & 4.29 & 5.31 \\
\hline 23 & 0.91 & 0.05 & 0.96 & 1.48 & 0.05 & 1.53 & 0.91 & 0.05 & 0.96 & 0.96 & 4.02 & 4.98 \\
\hline 24 & 0.51 & 0.03 & 0.54 & 0.80 & 0.03 & 0.83 & 0.51 & 0.03 & 0.54 & 0.54 & 2.20 & 2.73 \\
\hline
\end{tabular}

Table A5. Comparison between the hourly phase voltages calculated with different algorithms, at the level of the farthest pillar P95, [V].

\begin{tabular}{|c|c|c|c|c|c|c|c|c|c|c|c|c|}
\hline \multirow{2}{*}{ Hour } & \multicolumn{3}{|c|}{ SMD (Proposed) } & \multicolumn{3}{|c|}{ MCLA } & \multicolumn{3}{|c|}{ PSO } & \multicolumn{3}{|c|}{ GA } \\
\hline & a & $\mathbf{b}$ & c & a & $\mathbf{b}$ & c & a & b & c & $\mathbf{a}$ & b & c \\
\hline 1 & 223.25 & 222.85 & 222.25 & 223.28 & 219.05 & 225.96 & 222.50 & 222.46 & 223.38 & 223.81 & 221.64 & 222.90 \\
\hline 2 & 223.62 & 222.55 & 223.27 & 223.55 & 219.75 & 226.08 & 222.87 & 222.78 & 223.78 & 224.12 & 222.13 & 223.18 \\
\hline 3 & 224.01 & 222.94 & 223.69 & 223.91 & 220.40 & 226.29 & 223.28 & 223.20 & 224.17 & 224.45 & 222.65 & 223.54 \\
\hline 4 & 223.29 & 223.60 & 223.67 & 223.79 & 220.47 & 226.25 & 223.20 & 223.17 & 224.18 & 224.47 & 222.60 & 223.47 \\
\hline 5 & 223.33 & 223.55 & 223.59 & 223.82 & 220.35 & 226.26 & 223.30 & 223.07 & 224.10 & 224.35 & 222.57 & 223.55 \\
\hline 6 & 224.24 & 224.12 & 224.45 & 224.80 & 221.03 & 226.94 & 224.38 & 223.89 & 224.55 & 224.75 & 223.43 & 224.63 \\
\hline 7 & 223.33 & 223.16 & 223.14 & 223.26 & 219.58 & 226.72 & 223.09 & 223.16 & 223.38 & 223.64 & 222.57 & 223.42 \\
\hline 8 & 221.59 & 223.17 & 222.75 & 222.20 & 218.58 & 226.65 & 222.23 & 222.67 & 222.60 & 222.95 & 221.91 & 222.65 \\
\hline 9 & 221.36 & 222.83 & 221.88 & 221.84 & 218.08 & 226.07 & 221.69 & 222.03 & 222.35 & 222.69 & 221.29 & 222.08 \\
\hline 10 & 222.22 & 221.81 & 221.69 & 221.95 & 218.13 & 225.57 & 221.54 & 221.62 & 222.55 & 222.90 & 220.91 & 221.90 \\
\hline 11 & 220.73 & 221.02 & 221.25 & 220.94 & 217.16 & 224.83 & 220.43 & 220.62 & 221.95 & 222.37 & 219.82 & 220.81 \\
\hline 12 & 221.37 & 221.86 & 221.91 & 223.84 & 216.11 & 225.09 & 221.04 & 221.36 & 222.74 & 223.15 & 220.59 & 221.39 \\
\hline 13 & 222.15 & 220.28 & 221.45 & 223.49 & 215.53 & 224.75 & 220.57 & 220.86 & 222.45 & 222.89 & 220.05 & 220.93 \\
\hline 14 & 220.97 & 221.41 & 221.57 & 221.44 & 217.53 & 224.91 & 220.80 & 220.86 & 222.29 & 222.72 & 220.05 & 221.18 \\
\hline 15 & 221.95 & 220.37 & 221.35 & 221.37 & 217.39 & 224.85 & 220.71 & 220.76 & 222.20 & 222.70 & 219.83 & 221.14 \\
\hline 16 & 221.78 & 222.27 & 222.22 & 222.47 & 218.35 & 225.39 & 221.77 & 221.59 & 222.89 & 223.26 & 220.89 & 222.11 \\
\hline 17 & 221.85 & 220.34 & 221.23 & 221.31 & 217.20 & 224.85 & 220.73 & 220.63 & 222.06 & 222.56 & 219.66 & 221.19 \\
\hline 18 & 220.60 & 219.18 & 220.24 & 220.17 & 215.27 & 224.49 & 219.58 & 219.62 & 220.82 & 221.41 & 218.47 & 220.14 \\
\hline 19 & 220.78 & 220.07 & 221.17 & 220.96 & 215.62 & 225.34 & 220.40 & 220.60 & 221.03 & 221.63 & 219.37 & 221.01 \\
\hline 20 & 222.07 & 220.89 & 221.23 & 221.49 & 216.34 & 226.24 & 221.15 & 221.66 & 221.38 & 221.99 & 220.40 & 221.80 \\
\hline 21 & 220.83 & 218.92 & 220.42 & 221.29 & 214.22 & 224.53 & 219.60 & 220.66 & 219.91 & 220.66 & 219.12 & 220.39 \\
\hline 22 & 219.25 & 218.58 & 218.94 & 218.90 & 211.59 & 225.06 & 218.19 & 219.03 & 218.55 & 219.41 & 217.28 & 219.07 \\
\hline 23 & 218.81 & 218.91 & 218.98 & 219.75 & 212.05 & 224.71 & 218.55 & 219.04 & 219.11 & 219.98 & 217.33 & 219.38 \\
\hline 24 & 222.11 & 221.24 & 222.09 & 222.58 & 217.10 & 225.67 & 221.60 & 221.57 & 222.27 & 222.74 & 220.64 & 222.06 \\
\hline
\end{tabular}




\section{References}

1. Toader, C.; Porumb, R.; Bulac, C.; Tristiu, I. A perspective on current unbalance in low voltage distribution network. In Proceedings of the 9th International Symposium on Advanced Topics in Electrical Engineering (ATEE), Bucharest, Romania, 7-9 May 2015; pp. 741-746.

2. Chembe, D.K. Reduction of Power Losses Using Phase Load Balancing Method in Power Networks. In Proceedings of the World Congress on Engineering and Computer Science (WCECS 2009), San Francisco, CA, USA, 20-22 October 2009; Volume 1.

3. Beharrysingh, S. Phase Unbalance on Low-Voltage Electricity Networks and Its Mitigation Using Static Balancers. Ph.D. Thesis, Loughborough University, Loughborough, UK, 2014. Available online: https: //dspace.lboro.ac.uk/dspace-jspui/handle/2134/16252 (accessed on 1 February 2020).

4. Arias, J.; Calle, M.; Turizo, D.; Guerrero, J.; Candelo-Becerra, J.E. Historical Load Balance in Distribution Systems Using the Branch and Bound Algorithm. Energies 2019, 12, 1219. [CrossRef]

5. Homaee, O.; Najafi, A.; Dehghanian, M.; Attar, M.; Falaghi, H. A practical approach for distribution network load balancing by optimal re-phasing of single phase customers using discrete genetic algorithm. Int. Trans. Electr. Energy Syst. 2019, 29, e2834. [CrossRef]

6. Li, Y.; Gong, Y. Design of Three Phase Load Unbalance Automatic Regulating System for Low Voltage Power Distribution Grids. In MATEC Web of Conferences; EDP Science: Les Ulis, France, 2018; Volume 173, p. 02040.

7. Safitri, N.; Shahnia, F.; Masoum, M. Coordination of single-phase rooftop PVs in unbalanced three-phase residential feeders for voltage profiles improvement. Aust. J. Electr. Electron. Eng. 2016, 13, 77-90. [CrossRef]

8. Siti, M.W.; Jimoh, A.A.; Nicolae, D.V. Distribution network phase load balancing as a combinatorial optimization problem using fuzzy logic and Newton-Raphson. Electr. Power Syst. Res. 2011, 81, 1079-1087. [CrossRef]

9. Sicchar, J.R.; Da Costa, C.T., Jr.; Silva, J.R.; Oliveira, R.C.; Oliveira, W.D. A Load-Balance System Design of Microgrid Cluster Based on Hierarchical Petri Nets. Energies 2018, 11, 3245. [CrossRef]

10. Siti, M.W.; Jimoh, A.A.; Nicolae, D.V. LV self balancing distribution network reconfiguration for minimum losses. In Proceedings of the IEEE Bucharest Power Tech, Bucharest, Romania, 28 June-2 July 2009; pp. 1-6.

11. Esfandeh, M.A. Load Balancing Using a Best-Path-Updating Information-Guided Ant Colony Optimization Algorithm. J. Nov. Res. Electr. Power 2019, 7, 37-45.

12. Kalesar, B.M. Customers swapping between phases for loss reduction considering daily load profile model in smart grid. In Proceedings of the CIRED Workshop 2016, Helsinki, Finland, 14-15 June 2016; pp. 1-4.

13. Shahnia, F.; Wolfs, P.J.; Ghosh, A. Voltage Unbalance Reduction in Low Voltage Feeders by Dynamic Switching of Residential Customers among Three Phases. IEEE Trans. Smart Grid 2014, 5, 1318-1327. [CrossRef]

14. Bao, G.; Ke, S. Load Transfer Device for Solving a Three-Phase Unbalance Problem Under a Low-Voltage Distribution Network. Energies 2019, 12, 2842. [CrossRef]

15. Rios, M.A.; Castaño, J.C.; Garcés, A.; Molina-Cabrera, A. Phase Balancing in Power Distribution Systems: A heuristic approach based on group-theory. In Proceedings of the IEEE Milan Power Tech, Milan, Italy, 23-27 June 2019; pp. 1-6.

16. Mahendran, G.; Govindaraju, C. Flower Pollination Algorithm for Distribution System Phase Balancing Considering Variable Demand. Microprocess. Microsyst. 2020. [CrossRef]

17. Ivanov, O.; Neagu, B.C.; Gavrilas, M.; Grigoras, G.; Sfintes, C. Phase Load Balancing in Low Voltage Distribution Networks Using Metaheuristic Algorithms. In Proceedings of the International Conference on Electromechanical and Energy Systems (SIELMEN), Craiova, Romania, 9-11 October 2019; pp. 1-6.

18. Ali, B.; Siddique, I. Distribution system loss reduction by automatic transformer load balancing. In Proceedings of the International Multi-topic Conference (INMIC), Lahore, Pakistan, 24-26 November 2017; pp. 1-5.

19. Fäßler, B.; Schuler, M.; Kepplinger, P. Autonomous, Decentralized Battery Storage Systems for Load Balancing in Low Voltage Distribution Grids. In Proceedings of the 7th International Symposium on Energy, Manchester, UK, 14 August 2017.

20. Faessler, B.; Schuler, M.; Preißinger, M.; Kepplinger, P. Battery Storage Systems as Grid-Balancing Measure in Low-Voltage Distribution Grids with Distributed Generation. Energies 2017, 10, 2161. [CrossRef] 
21. Liu, X.; Jia, J.; Wang, J. Research of Three-Phase Unbalanced Treatment in Low-Voltage Distribution Network Based on New Commutation Switch. World J. Eng. Technol. 2019, 7, 10-17. [CrossRef]

22. Kharche, R.; Diwane, A.; Bhalerao, B.; Jhadhav, A.; More, S.M.; Shinde, G.H. Automatic Load Balancing and Phase Balancing By PLC and SCADA. In Proceedings of the International Conference on New Frontiers of Engineering, Management, Social Science and Humanities, Pune, India, 27 May 2018; pp. 174-179.

23. Kardam, N.; Ansari, M.A. Farheen, Communication and load balancing using SCADA model based integrated substation. In Proceedings of the International Conference on Energy Efficient Technologies for Sustainability, Nagercoil, India, 10-12 April 2013; pp. 1256-1261.

24. Pasdar, A.; Mehne, H.H. Intelligent three-phase current balancing technique for single-phase load based on smart metering. Int. J. Electr. Power Energy Syst. 2011, 33, 693-698. [CrossRef]

25. Bordagaray, A.G.; Prado, J.G.; Vélez, M. Optimal Phase Swapping in Low Voltage Distribution Networks Based on Smart Meter Data and Optimization Heuristics. In Harmony Search Algorithm: Proceedings of the 3rd International Conference on Harmony Search Algorithm (ICHSA 2017); Springer: Singapore, 2017; Volume 514, p. 283.

26. Pires, V.; Santos, N.M.; Cordeiro, A.; Sousa, J.L. Balancing LV Distribution Networks in the Context of the Smart Gird. Int. J. Smart Grid 2019, 3, 42-53.

27. Grigoras, G.; Gavrilas, M.; Neagu, B.C.; Ivanov, O.; Triștiu, I.; Bulac, C. Efficient Method to Optimal Phase Load Balancing in Low Voltage Distribution Network. In Proceedings of the Int. Conf. on Energy and Environment (CIEM), Timisoara, Romania, 17-18 October 2019; pp. 323-327.

28. Ivanov, O.; Grigoras, G.; Neagu, B.C. Smart Metering based Approaches to Solve the Load Phase Balancing Problem in Low Voltage Distribution Networks. In Proceedings of the International Symposium on Fundamentals of Electrical Engineering (ISFEE), Bucharest, Romania, 1-3 November 2018; pp. 1-6.

29. Tung, T.A.; Son, T.T. Current unbalance reduction in low voltage Distribution networks using automatic phase balancing device. Vietnam J. Sci. Technol. 2017, 55, 108-119. [CrossRef]

30. Tung, N.X.; Fujita, G.; Horikoshi, K. Phase loading balancing by shunt passive compensator. In Proceedings of the 2009 Transmission \& Distribution Conference \& Exposition: Asia and Pacific, Seoul, Korea, 26-30 October 2009; pp. 1-4.

31. Siti, M.W.; Nicolae, D.V.; Jordaan, J.A.; Jimoh, A.A. Distribution Feeder Phase Balancing Using Newton-Raphson Algorithm-Based Controlled Active Filter. In Proceedings of the International Conference on Neural Information Processing, Kitakyushu, Japan, 13-16 November 2007; Springer: Berlin/Heidelberg, Germany; pp. 713-720.

32. Zheng, Y.; Zou, L.; He, J.; Su, Y.; Feng, Z. Fast Unbalanced Three-phase Adjustment based on Single-phase Load Switching. Telekomnika Indones. J. Electr. Eng. 2013, 11, 4327-4334.

33. Novatek-Electro. Available online: https://novatek-electro.com/en/products/phase-selector-switch/universalautomatic-electronic-phase-switch-pef-301.html (accessed on 1 February 2020).

34. Henderieckx, H. Smart Metering Device with Phase Selector. Available online: https://patents.google.com/ patent/US20120078428A1/en (accessed on 1 February 2020).

35. Grigoras, G. Impact of Smart Meter Implementation on Saving Electricity in Distribution Networks in Romania. Chapter in Book: Application of Smart Grid Technologies Case Studies in Saving Electricity in Different Parts of the World; Academic Press: London, UK, 2018; pp. 313-346.

36. Grigoras, G.; Neagu, B.-C. Smart Meter Data-Based Three-Stage Algorithm to Calculate Power and Energy Losses in Low Voltage Distribution Networks. Energies 2019, 12, 3008. [CrossRef]

37. Pillary, P.; Manyage, M. Definitions of voltage unbalance. IEEE Power Eng. Rev. 2001, 21, 50-51. [CrossRef]

38. Romanian Energy Regulatory Authority. Report on the Performance Indicators for Electric Transmission, System and Distribution Services and the Technical State of Electric Transmission and Distribution Networks in 2018 (in Romanian), Romania. 2019. Available online: https://www.anre.ro/ro/energie-electrica/rapoarte/ rapoarte-indicatori-performanta (accessed on 1 February 2020).

39. Baričević, T.; Skok, M.; Majstrović, G.; Perić, K.; Brajković, J. South East European Distribution System Operators Benchmarking Study. Available online: https://www.usea.org/sites/default/files/SEE\%20DSO\% 20Benchmarking\%20Study\%202008\%20-\%202015\%20-\%20final.pdf (accessed on 1 February 2020).

40. Romanian Energy Regulatory Authority. Normative for the Design of the Electrical Networks of Public Distribution-PE 132/2003. 2003. Available online: https://www.anre.ro/ro/legislatie/norme-tehnice/normativetehnice-energetice-nte (accessed on 1 February 2020). 
41. Han, S.; Kodaira, D.; Han, S.; Kwon, B.; Hasegawa, Y.; Aki, H. An Automated Impedance Estimation Method in Low-Voltage Distribution Network for Coordinated Voltage Regulation. IEEE Trans. Smart Grid 2016, 7, 1012-1020. [CrossRef]

42. Zhu, J.; Chow, M.Y.; Zhang, F. Phase Balancing using Mixed-Integer Programming. IEEE Trans. Power Syst. 1998, 13, 1487-1492. article distributed under the terms and conditions of the Creative Commons Attribution (CC BY) license (http://creativecommons.org/licenses/by/4.0/). 